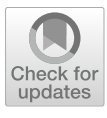

Cite as

Nano-Micro Lett.

(2020) 12:15

Received: 28 September 2019

Accepted: 17 November 2019

Published online: 3 January 2020

(C) The Author(s) 2020

\section{Recent Advances in Tumor Microenvironment Hydrogen Peroxide-Responsive Materials for Cancer Photodynamic Therapy}

\author{
Nan Yang ${ }^{1}$, Wanyue Xiao ${ }^{1}$, Xuejiao Song $^{1} \bowtie$, Wenjun Wang $^{2}$, Xiaochen Dong ${ }^{1,3} \bowtie$ \\ $\triangle$ Xuejiao Song, xjsong@njtech.edu.cn; Xiaochen Dong, iamxcdong@njtech.edu.cn \\ 1 Key Laboratory of Flexible Electronics (KLOFE) and Institute of Advanced Materials (IAM), School \\ of Physical and Mathematical Sciences, Nanjing Tech University (Nanjing Tech), Nanjing 211800, \\ People's Republic of China \\ 2 School of Physical Science and Information Technology, Liaocheng University, Liaocheng 252059, \\ People's Republic of China \\ 3 School of Chemistry and Materials Science, Nanjing University of Information Science and Technology, \\ Nanjing 210044, People's Republic of China
}

\title{
HIGHLIGHTS
}

- The reaction mechanism of various kinds of nanomaterials with endogenous $\mathrm{H}_{2} \mathrm{O}_{2}$ is outlined.

- The design and application guideline for various $\mathrm{H}_{2} \mathrm{O}_{2}$-responsive nanomaterials in photodynamic therapy (PDT) are reviewed.

- The development and prospect of various $\mathrm{H}_{2} \mathrm{O}_{2}$-response nanomaterials for PDT and clinical application are envisioned.

\begin{abstract}
Photodynamic therapy (PDT), as one of the noninvasive clinical cancer phototherapies, suffers from the key drawback associated with hypoxia at the tumor microenvironment (TME), which plays an important role in protecting tumor cells from damage caused by common treatments. High concentration of hydrogen peroxide $\left(\mathrm{H}_{2} \mathrm{O}_{2}\right)$, one of the hallmarks of TME, has been recognized as a double-edged sword, posing both challenges, and opportunities for cancer therapy. The promising perspectives, strategies, and approaches for enhanced tumor therapies, including PDT, have been developed based on the fast advances in $\mathrm{H}_{2} \mathrm{O}_{2}$-enabled theranostic nanomedicine. In this review, we outline the latest advances in $\mathrm{H}_{2} \mathrm{O}_{2}$-responsive materials, including organic and inorganic materials for enhanced PDT. Finally, the challenges and opportunities for further research on $\mathrm{H}_{2} \mathrm{O}_{2}$-responsive anticancer agents are envisioned.
\end{abstract}

KEYWORDS Tumor microenvironment; $\mathrm{H}_{2} \mathrm{O}_{2}$-responsive; Cancer; Nanomaterials; Photodynamic therapy

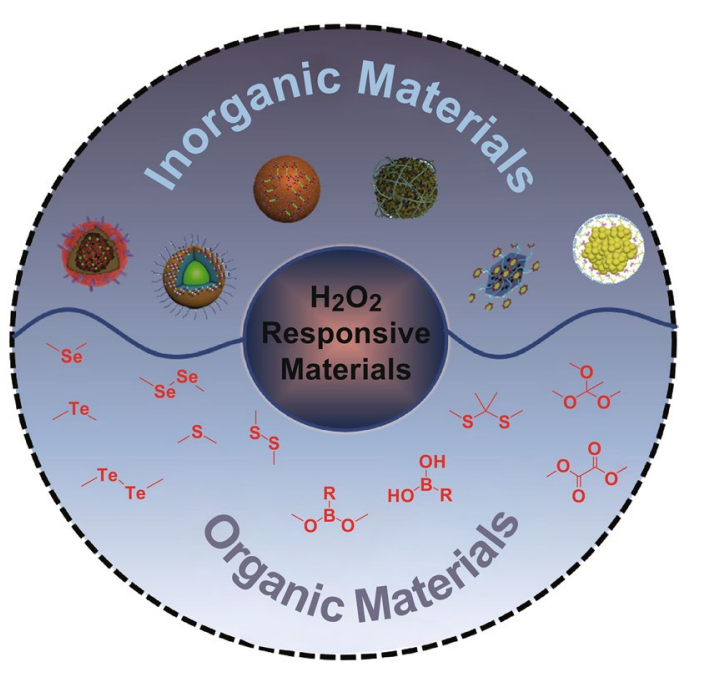

\section{Introduction}

Cancer is one of the leading threats to human health and development [1]. Traditional cancer therapies, including surgery, chemotherapy, and radiotherapy, have their inherent drawbacks despite being used clinically for decades [2]. For example, surgery is generally applied to remove tumors for biopsy. But it is not applicable for leukemia and metastatic cancers. Chemotherapy and radiotherapy are usually the main treatments for terminal cancer. However, these 
traditional therapeutic methods are always accompanied by serious drug resistance and severe side effects, which cause the patients suffering [3]. With the development of nanomaterials, photodynamic therapy (PDT), employing a lightexcited photosensitizer (PS) to generate reactive oxygen species (ROS) in the presence of oxygen $\left(\mathrm{O}_{2}\right)$, has received increasing attention owing to its low systemic toxicity, high selectivity, and minimal invasiveness compared with traditional therapies $[4,5]$.

TME is mainly composed of fibroblasts and myofibroblasts, neuroendocrine cells, adipose cells, immune, and inflammatory cells, the blood and lymphatic vascular networks, and extracellular matrix (ECM) [6]. Changes in the physiological state and function of TME lead to tumor progression. When TME is in its initial normal state, further invasion and metastasis of the tumor cells will be prevented by TME, but once TME is destroyed into an irreversible situation, it will become an accomplice to cancer deterioration. In addition, TME has been identified to be the indicator for determining abnormal tissue function and plays a key role in the subsequent evolution of persistent and advanced malignancies [7]. Due to the interaction between different stromal cells and active factors blocking TME, traditional strategies for tumor intervention and treatment are often unsatisfied. The blocking mechanism induced by the treatments could be quickly adapted and balanced by TME, which results in continued development and deterioration of cancer cells. Different from the traditional treatment strategies, PDT can promote cancer cell death by increasing the concentration of ROS in TME.

Singlet oxygen $\left({ }^{1} \mathrm{O}_{2}\right)$ is one of the most important ROS catalyzed by $\mathrm{O}_{2}$ in PDT [8]. However, TME is always hypoxic due to the characteristics of cancer cells including unlimited multiplication, evasion from growth suppressors, resisting apoptosis, stimulating angiogenesis, and elimination of cell energy limitation [9]. During the cell proliferation process, a large amount of $\mathrm{O}_{2}$ is consumed. Although the number of blood vessels is increased, the partial pressure of $\mathrm{O}_{2}$ in the blood vessels is greatly reduced and the $\mathrm{O}_{2}$ replenishing ability is lowered, which finally limits the efficiency of PDT $[10,11]$. To date, various methods have been developed to overcome tumor hypoxia and improve the efficiency of tumor treatment, such as hyperbaric $\mathrm{O}_{2}$ therapy, $\mathrm{O}_{2}$ delivery based on perfluorohexane, $\mathrm{O}_{2}$ generated by catalase-like nanomaterials, and anoxic therapy [12]. Furthermore, various intelligent systems that can respond to external stimuli (such as heat, irradiation or microwave) and internal stimuli (TME factors such as $\mathrm{H}_{2} \mathrm{O}_{2}$ or certain enzymes) are developed to improve the tumor-targeting efficiency of PSs, reduce the side effects, and enhance the efficacy of PDT [13].

$\mathrm{H}_{2} \mathrm{O}_{2}$ (half-life about $1 \mathrm{~ms}$ ) is relative stable as compared with other ROS (half-life $<1 \mu \mathrm{s}$ ). In addition, $\mathrm{H}_{2} \mathrm{O}_{2}$ acts as extracellular and intracellular signaling molecule that mediates multiple effects in biological systems, including recruitment of immune cells to damaged areas and cell migration. $\mathrm{H}_{2} \mathrm{O}_{2}$ is obtained from mitochondria generated superoxide ions in a process that is catalyzed by the overexpressed superoxide dismutase (SOD). Compared with normal cells, cancer cells show increased generation rate of $\mathrm{H}_{2} \mathrm{O}_{2}$ (up to $0.5 \mathrm{nmol} / 10^{4}$ cells $/ \mathrm{h}$ ) [8], resulting in a higher level of $\mathrm{H}_{2} \mathrm{O}_{2}$ in the tumor than normal tissues. In addition to its essential role in cellular signaling, overproduced $\mathrm{H}_{2} \mathrm{O}_{2}$ has been exploited as a major precursor for highly active ROS, such as hydroxyl radical, peroxynitrite, and hydrochlorides. Importantly, researchers have found that $\mathrm{H}_{2} \mathrm{O}_{2}$ accumulated in tumors can be decomposed to generate $\mathrm{O}_{2}$ under certain conditions, which is used to supplement the $\mathrm{O}_{2}$ required for PDT treatment. Since the accumulation of $\mathrm{H}_{2} \mathrm{O}_{2}$ can increase the oxidative stress and reflect the development of many diseases, taking $\mathrm{H}_{2} \mathrm{O}_{2}$ as a cancer diagnostic marker as well as a therapeutic target presents tremendous theranostic potential.

Up to now, many $\mathrm{H}_{2} \mathrm{O}_{2}$-responsive nanoplatforms based on inorganic or organic materials have been developed for enhancing anticancer PDT $[14,15]$. Due to the unique physicochemical properties, easy surface functionalization and good biocompatibility, inorganic materials have been widely utilized as therapeutic agents in biomedical field [16]. Simultaneously, phthalocyanine, boron dipyrromethene (BODIPY), porphyrin, chlorin e6 (Ce6), and their derivatives are the most common organic photoactive PSs in PDT due to their low dark toxicity, high stability, intense adsorption band, and high absorbance coefficient [17]. Here, we describe different categories of $\mathrm{H}_{2} \mathrm{O}_{2}$-responsive phototherapeutic platforms for cancer treatments (Scheme 1).

\section{Inorganic Materials for $\mathrm{H}_{2} \mathrm{O}_{2}$-Responsive Photodynamic Therapy}

Hypoxia at the tumor site has been reported to be the main cause of limited PDT efficiency. Strategies such as delivering $\mathrm{O}_{2}$ to the tumor site via perfluorocarbon-based $\mathrm{O}_{2}$ 


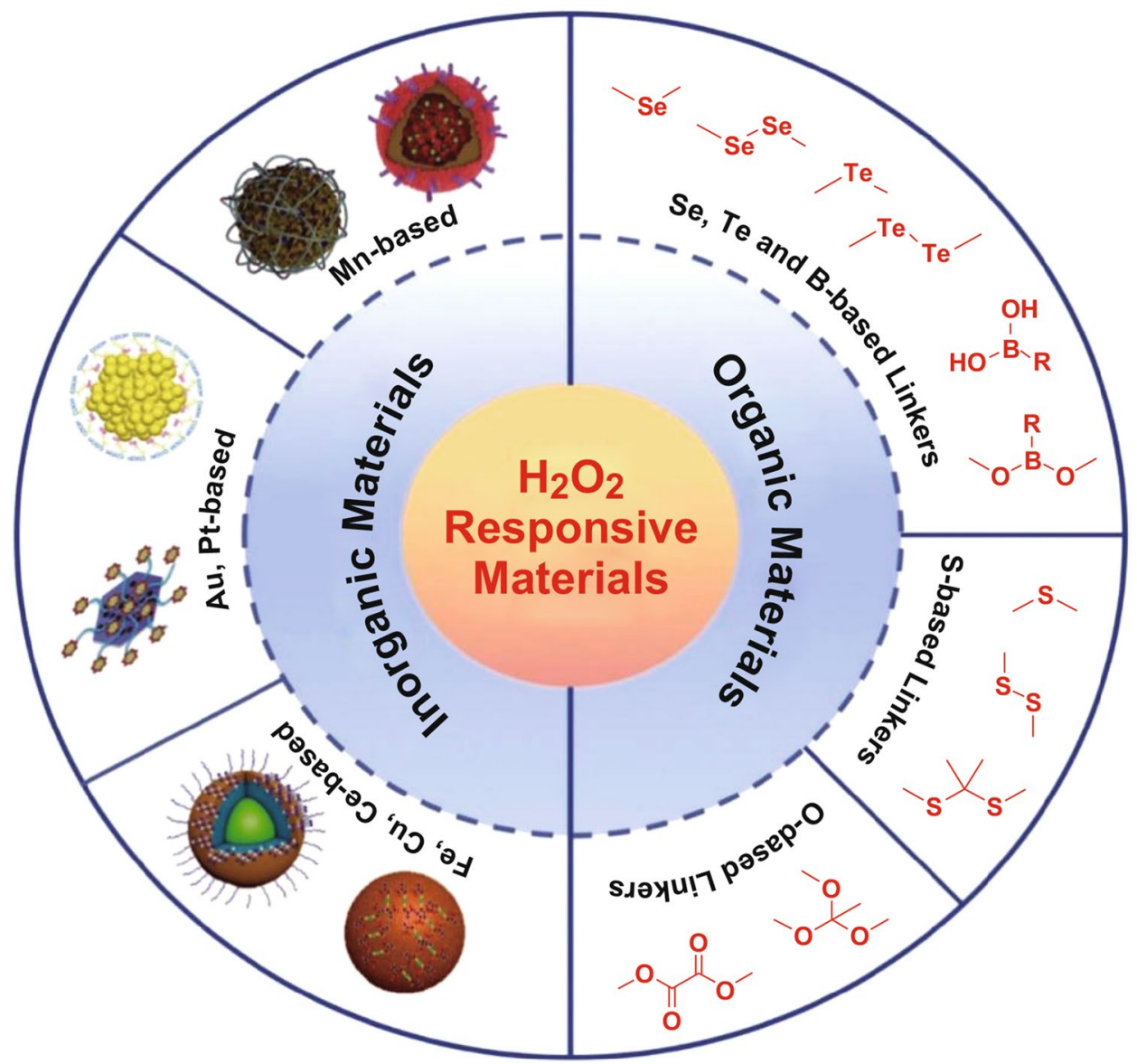

Scheme 1 Summary of $\mathrm{H}_{2} \mathrm{O}_{2}$-responsive materials for enhanced photodynamic therapy

carriers or reducing $\mathrm{O}_{2}$ consumption have been developed to relieve tumor hypoxia, thus improving $\mathrm{O}_{2}$ involved therapies. Meanwhile, taking advantage of high concentration of endogenous $\mathrm{H}_{2} \mathrm{O}_{2}$, in situ production of $\mathrm{O}_{2}$ inside the tumor by catalyst could be a more effective approach to overcome tumor hypoxia and enhance PDT. Inorganic nanomaterials have attracted increasing attention owing to their unique physical/chemical properties, versatile synthetic strategies, and easy surface functionalization [18]. Inorganic therapeutic agents based on manganese $(\mathrm{Mn})$, gold $(\mathrm{Au})$, platinum $(\mathrm{Pt})$, iron $(\mathrm{Fe})$, copper $(\mathrm{Cu})$, cerium $(\mathrm{Ce})$, chromium $(\mathrm{Cr})$, bismuth $(\mathrm{Bi})$, vanadium $(\mathrm{V})$, titanium (Ti), cobalt $(\mathrm{Co})$, and lanthanides have been applied to external or internal stimuli-responsive cancer therapies. Besides, mesoporous silica ( $\mathrm{Si}$ )-based materials, carbon-based materials like carbon dots (CDs) and semiconductors materials such as quantum dots (QDs) have also been utilized for cancer therapy [19]. In this section, endogenous $\mathrm{H}_{2} \mathrm{O}_{2}$-responsive inorganic materials for enhanced PDT, including $\mathrm{Mn}-$, Au-, $\mathrm{Pt}-, \mathrm{Fe}-, \mathrm{Cu}-$, and Ce-based materials, will be summarized.

\subsection{Mn-Based Materials}

In recent years, Mn-based nanostructures have attracted considerable interests in bio-applications. Manganese dioxide $\left(\mathrm{MnO}_{2}\right)$, the most common structure of manganese ions, shows high reactivity to acid and glutathione (GSH), being utilized as pH- or GSH-responsive drug delivery systems. Meanwhile, $\mathrm{MnO}_{2}$ nanoconstructs could decompose tumor endogenous $\mathrm{H}_{2} \mathrm{O}_{2}$ into $\mathrm{O}_{2}$, relieving tumor hypoxia. Different kinds of $\mathrm{MnO}_{2}$ nanoconstructs have been reported and made great progress in TME-enhanced tumor therapies [20]. Based on this, a unique multifunctional nanoplatform responsive to multiple parameters of TME with improved PDT efficiency has been reported. Multifunctional $\mathrm{pH}-/$ 
(a)

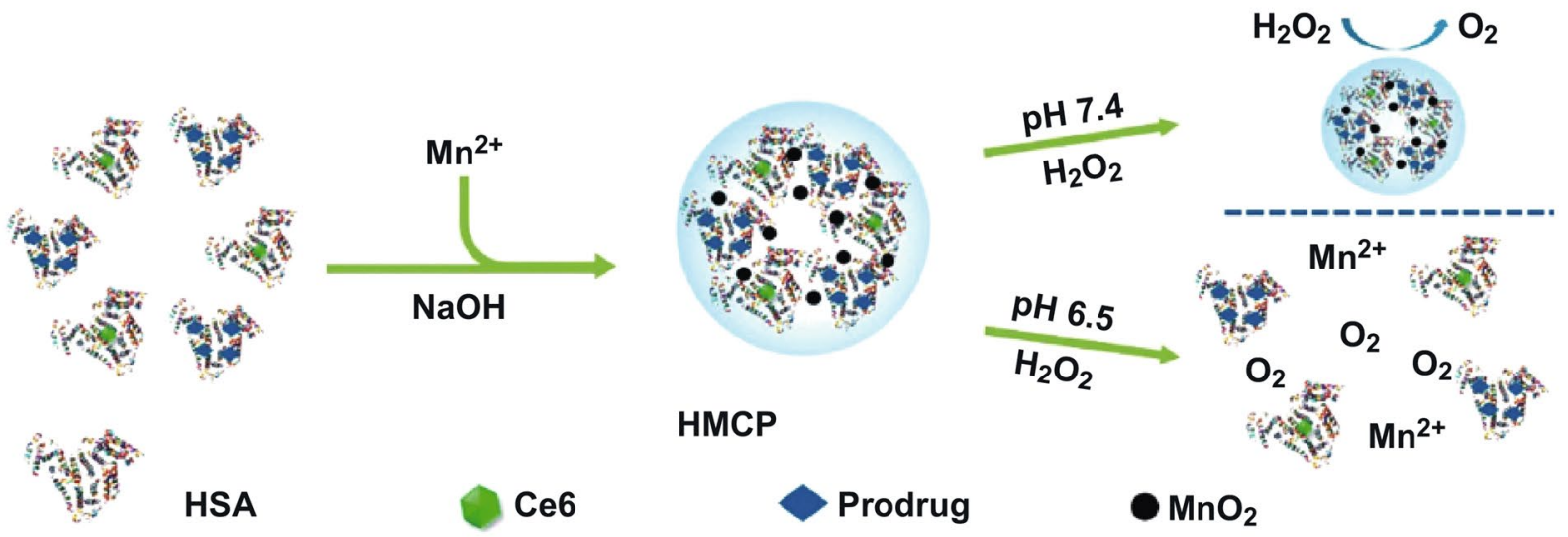

(b)

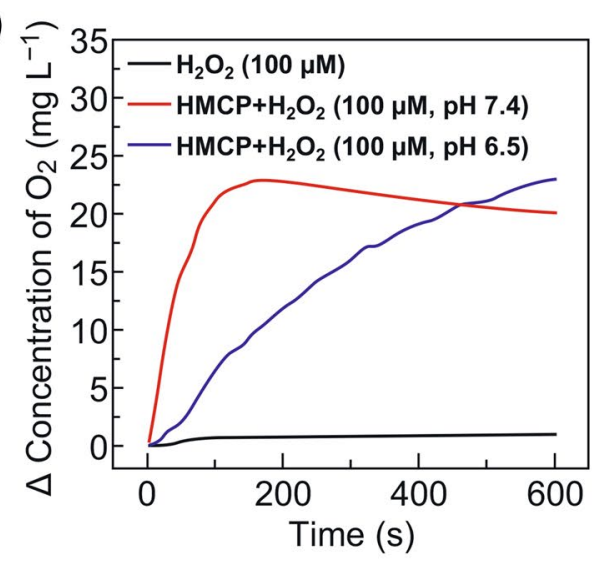

(c)
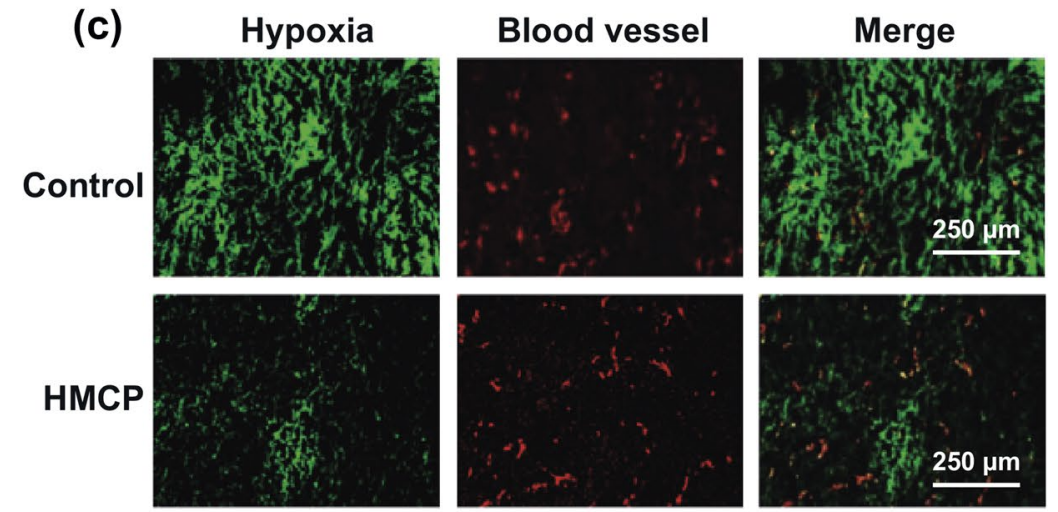

(d)

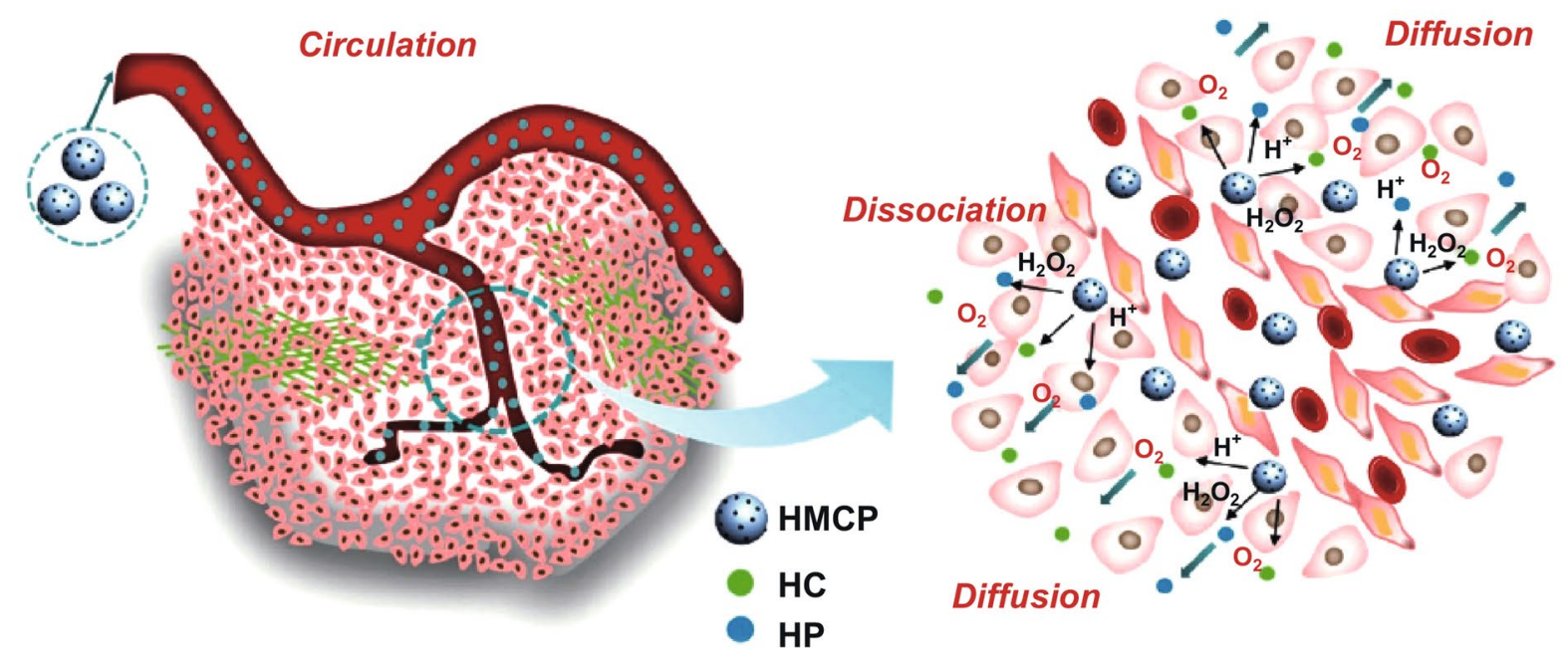

Fig. 1 a Schematic representation of the formation of HMCP nanoparticles. b HMCP was added at different pH values to generate oxygen in $\mathrm{H}_{2} \mathrm{O}_{2}$ solution $\left(100 \times 10^{-6} \mathrm{M}\right)$. The decrease in oxygen concentration in the sample at $\mathrm{pH} 7.4$ (after about $150 \mathrm{~s}$ ) is due to the rapid consumption of $\mathrm{H}_{2} \mathrm{O}_{2}$. c Representative immunofluorescence images of tumor sections after hypoxia staining. Hypoxic areas and blood vessels were stained with anti-pipemole antibody (green) and anti-CD31 antibody (red). d Scheme of the disintegration of HMCP nanoparticles by in situ chemical reaction in the TME for synergistic PDT and chemotherapy. Adapted with permission from Ref. [14]. Copyright 2016 Wiley-VCH 
$\mathrm{H}_{2} \mathrm{O}_{2}$-responsive nanoparticles (NPs) named $\mathrm{HSA}-\mathrm{MnO}_{2}$ Ce6\&Pt (HMCP) with an average size of about $50 \mathrm{~nm}$ were synthesized via a simple one-step biomineralization method (Fig. 1a) [14]. These HMCPs were able to decompose endogenous $\mathrm{H}_{2} \mathrm{O}_{2}$ to generate $\mathrm{O}_{2}$ in situ for overcoming tumor hypoxia-associated resistance of PDT (Fig. 1b, c). On the other hand, HMCP could be dissociated into individual albumin-based complexes with smaller sizes $(<10 \mathrm{~nm})$ in the acidic TME, resulting in enhanced intratumoral permeability for improved therapeutic outcomes of the synergistic
PDT/chemotherapy (Fig. 1d). This nano-treatment platform is designed with $\mathrm{MnO}_{2}$ as the core of nanomaterials.

Another strategy for designing nano-multi-functional platforms is to use $\mathrm{MnO}_{2}$ as nanoshell. Our group specifically designed a $\mathrm{H}_{2} \mathrm{O}_{2}$-responsive degradable nanoplatform by co-loading PS aza-BODIPY (SAB) and anticancer drug doxorubicin (DOX) into the hydrangea-structured $\mathrm{MnO}_{2}$ NPs for chemo/photodynamic/photothermal synergistic therapy (Fig. 2a). $\mathrm{MnO}_{2}$ in MDSP NPs can react with $\mathrm{H}_{2} \mathrm{O}_{2}$ and $\mathrm{H}^{+}$in TME to generate oxygen and overcome tumor (a)

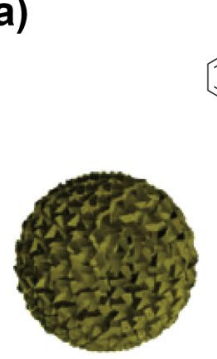

$\mathrm{MnO}_{2} \mathrm{NPs}$

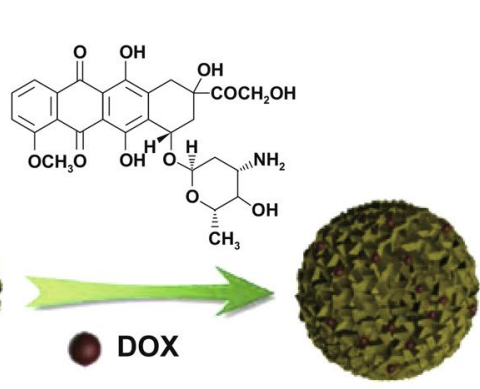

MD NPs

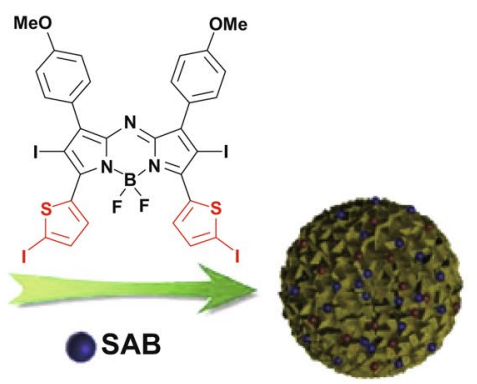

MDS NPS

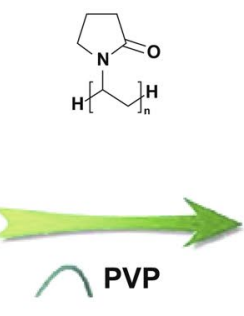

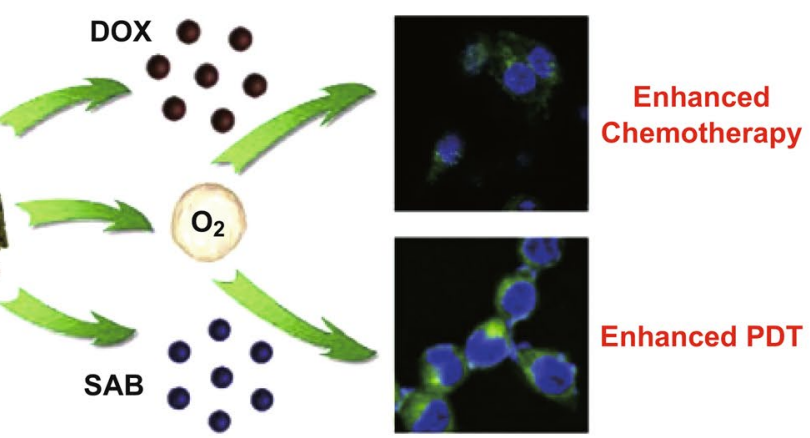

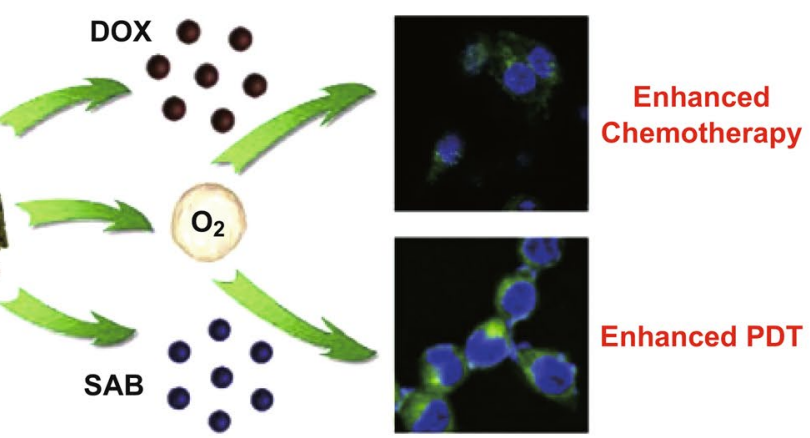

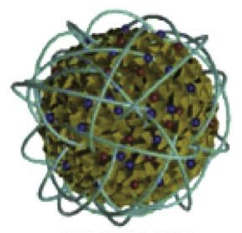

MDSP NPs (b)

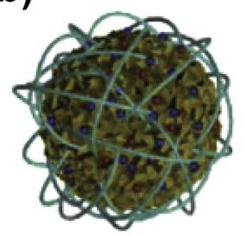

MDSP NPs
$\mathrm{H}_{2} \mathrm{O}_{2}, \mathrm{H}^{+}$

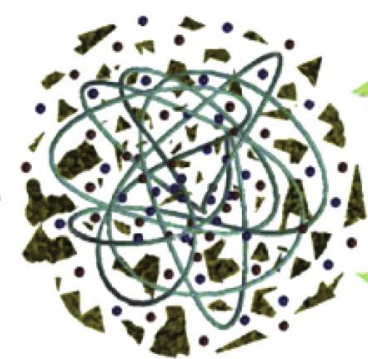

$\mathrm{MnO}_{2}+\mathrm{H}_{2} \mathrm{O}_{2}+2 \mathrm{H}^{+} \rightarrow \mathrm{O}_{2}+\mathrm{Mn}^{2+}+2 \mathrm{H}_{2} \mathrm{O}$ (c)

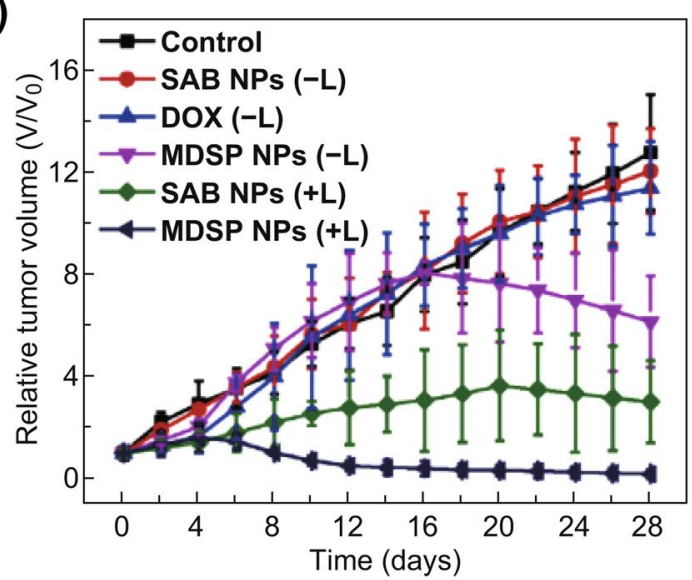

(d)

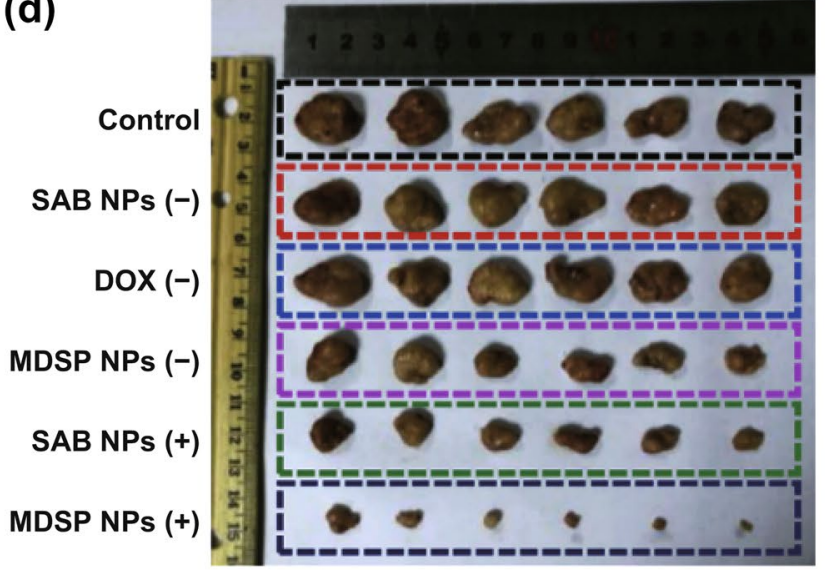

Fig. 2 a Schematic diagram of MDSP NPs manufacturing. b Schematic illustration of MDSP NPs for TME-responsive chemo/photodynamic therapy. c Tumor growth curves of differently treated mice (6 mice/group). d Tumor photographs collected from mice in different treatment groups. Adapted with permission from Ref. [21]. Copyright 2019 Elsevier Ltd 
hypoxia (Fig. 2b) [21]. Injection of MDSP NPs combined with laser radiation showed the highest tumor inhibition efficiency. Both in vitro and in vivo studies demonstrated the promotion of TME-responsive oxygen-self-generation and excellent chemo/photodynamic/photothermal synergistic therapy of MDSP NPs (Fig. 2c-d).

In addition to tumor hypoxia, PDT also suffers from neutralization by excess GSH in the TME. Reducing tumor GSH levels could benefit to enhance PDT efficiency. It was found that $\mathrm{MnO}_{2}$ could consume the intratumoral GSH. For example, Nie's group developed a photosensitive porphyrinic Zr-MOF (PCN-224) nanostructure, which was loaded with vascular endothelial growth factor receptor 2 (VEGFR2) inhibitor apatinib and coated with a $\mathrm{MnO}_{2}$ layer (aMMTm, Fig. 3a) [22]. The tumor-targeting aMMTm NPs could be utilized as drug delivery vehicle and the $\mathrm{MnO}_{2}$ layer could neutralize excessive intratumoral GSH. Both in vitro and in vivo experiment showed the excellent anticancer

(a)
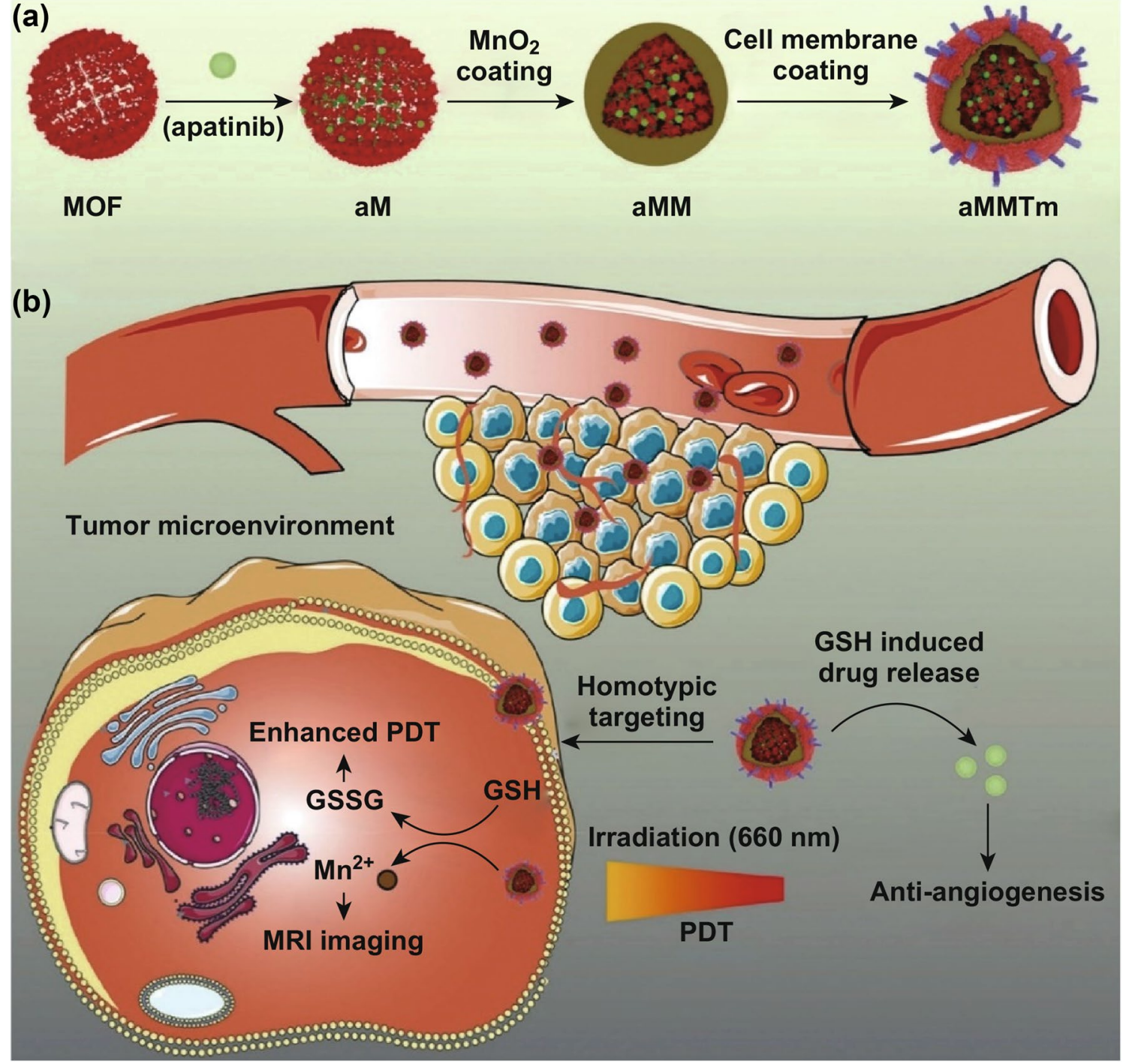

Fig. 3 a Porphyrin metal-organic framework nanoparticle aMMTm was constructed by drug loading, $\mathrm{MnO}_{2}$ coating and tumor cell membrane decoration. b The proposed mechanism of action of aMMTm in mouse tumor model. Tumor cell membrane camouflage can help the early removal of nanoparticles and target tumor through homotypic affinity. At tumor site, $\mathrm{MnO}_{2}$ shell reacts with GSH in the microenvironment or tumor cells, consuming excess GSH and enhancing the action of PDT. Simultaneously produced $\mathrm{Mn}^{2+}$ can be used as MRI contrast agent. When $\mathrm{MnO}_{2}$ shell degrades, the released apatinib neutralizes PDT-induced revascularization and prevents tumor progression. Adapted with permission from Ref. [22]. Copyright 2019 WILEY-VCH 
efficiency of aMMTm NPs when compared with NPs without targeting ligand or $\mathrm{MnO}_{2}$ (Fig. 3b). Most importantly, Mn-based nanomaterials not only specifically trigger the breakdown of endogenous $\mathrm{H}_{2} \mathrm{O}_{2}$ under acidic conditions of TME, but also neutralize excess GSH, giving them great potential for further integration with other therapies.

\subsection{Au-Based Materials}

Because of the low-toxic, chemically stable and easy functionalization, Au-based nanomaterials, including nanospheres, nanorods, nanoshells, and nanocages, have been widely explored for biomedical applications [23-29]. Due to the excellent photoabsorption and thermal conductivity of $\mathrm{Au}, \mathrm{Au}$-based nanomaterials are mostly employed as photothermal agents [30]. Au itself cannot be utilized as PSs to generate ROS directly, but it can enhance PDT efficiency by triggering PSs to achieve high ${ }^{1} \mathrm{O}_{2}$ quantum yield based on the luminescence resonance energy transfer (LRET) effect or by transferring energy to molecular oxygen for sensitizing the formation of ${ }^{1} \mathrm{O}_{2}$ due to localized surface plasmon resonance (LSPR) [31]. In addition, LSPR of the gold nanorods, nanoshells and nanocage can be easily adjusted to the NIR region, enabling deeper tissue penetration and less photodamage [18]. As far as we known, few studies focused on Au-based $\mathrm{H}_{2} \mathrm{O}_{2}$-responsive materials for enhanced PDT have been reported till now.

The latest research about Au-based materials for $\mathrm{H}_{2} \mathrm{O}_{2}$-responsive phototherapy is reported by Lin's group [32]. They successfully obtained amine-terminated PAMAM dendrimer encapsulated gold nanoclusters (AuNCs- $\mathrm{NH}_{2}$, Fig. 4a). The AuNCs- $\mathrm{NH}_{2}$ triggered oxygen production by reacting with $\mathrm{H}_{2} \mathrm{O}_{2}$ via the catalase-like activity in acidic TME. The proposed mechanism is that tertiary amines of dendrimers are easily protonated in acidic TME. The protonated products promote the pre-adsorption of $\cdot \mathrm{OH}$ on the metal surface, thus facilitating the intrinsic catalase-like reaction. With protoporphyrin IX (PpIX) in this platform, oxygen produced by AuNCs- $\mathrm{NH}_{2}$ via catalase-like reaction could be further converted into ${ }^{1} \mathrm{O}_{2}$, thus enhancing the photodynamic therapeutic efficiency to some extent (Fig. 4b). However, due to the limited penetration of the visible light used to activate PSs, their strategy was only demonstrated in vitro rather than in vivo. This problem has been solved in another research by Liu and co-workers [33]. In their work, a gold nanorod-based NIR-II-responsive nanosystem was constructed, which was named as AuNC@HSA/CAT. Alkylthiolated gold nanoclusters (AuNCs) were co-modified with human serum albumin (HSA) and catalase (CAT) (Fig. 4c), which could be further used as a multifunctional nanoparticle. Under $1064 \mathrm{~nm}$ laser irradiation, cancer cell apoptosis could be achieved by chemically generated ${ }^{1} \mathrm{O}_{2}$ and plasmonic heating from the gold nanorods with lower tissue absorption and scattering (Fig. 4d). Moreover, the presence of CAT in the nanoparticles triggered the decomposition of tumor endogenous $\mathrm{H}_{2} \mathrm{O}_{2}$ to generate oxygen, thereby enhancing the efficacy of PDT by relieving tumor hypoxia (Fig. 4e).

\subsection{Pt-Based Materials}

Like Au-based nanomaterials, Pt-based nanomaterials can be easily surface-modified, combined with other drugs and demonstrate great ability to catalyze $\mathrm{H}_{2} \mathrm{O}_{2}$. Based on this, researchers try to develop several novel types of inorganic materials based on platinum for tumor PDT. One work worth mentioning is reported by Zheng's group [34]. The authors chose Pd@Pt nanosheets as the substrate to covalently link with PS Ce6. After modification with PEG, the obtained Pd@Pt-PEG-Ce6 nanoplatform showed catalaselike activity, thus decomposing $\mathrm{H}_{2} \mathrm{O}_{2}$ into oxygen. Meanwhile, mild photothermal effects induced by Pd@Pt-PEGCe6 could increase intratumoral blood flow and enhance cellular uptake of PSs, leading to in situ $\mathrm{O}_{2}$ supplementation. Remarkably enhanced photodynamic therapy and photothermotherapy (PDT and PTT) were achieved both in vitro and in vivo owing to the relieved tumor hypoxia. In another work reported by Zhang's group [35], Pt-based core-shell nanoplatform (Pda-Pt@PCN-FA) was developed for enhanced PDT via oxygen generation (Fig. 5a). Dopamine core was mixed with $\mathrm{H}_{2} \mathrm{PtCl}_{6}$, which was employed as Pt-based interlayer named Pda-Pt. Then, it was incorporated in zirconium-porphyrin (PCN) shell and immobilized with targeting ligands folic acid (FA) for enhanced tumor accumulation and desirable therapeutic efficacy. The Pt-based interlayer in this nanosystem could decompose endogenous $\mathrm{H}_{2} \mathrm{O}_{2}$ into $\mathrm{O}_{2}$, just like an oxygen-generation nanofactory (Fig. 5b). Under light irradiation, PCN shells converted the produced $\mathrm{O}_{2}$ into ROS, resulting in enhanced therapeutic efficacy of PDT. Meanwhile, $\mathrm{O}_{2}$ produced by 

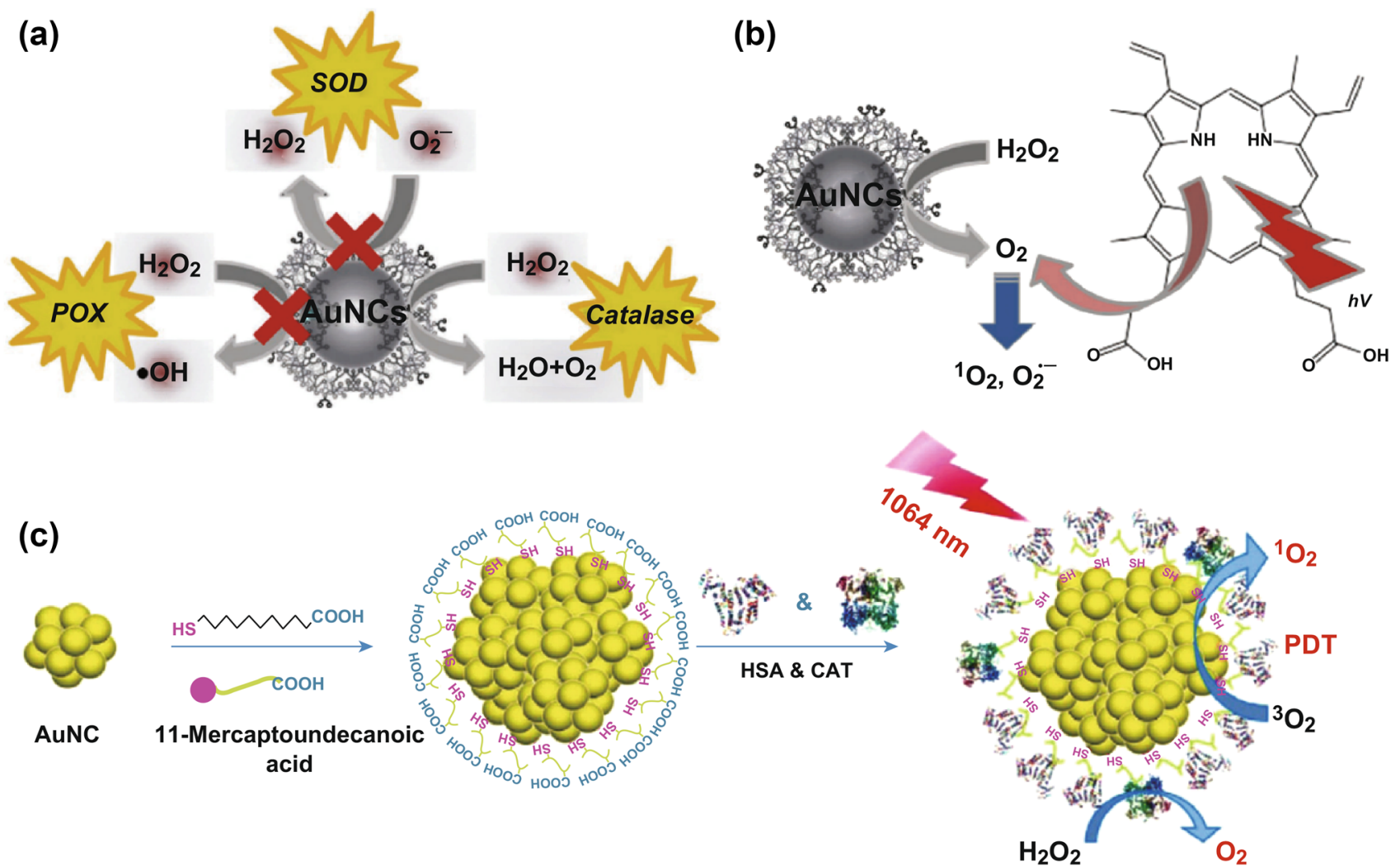

(d)

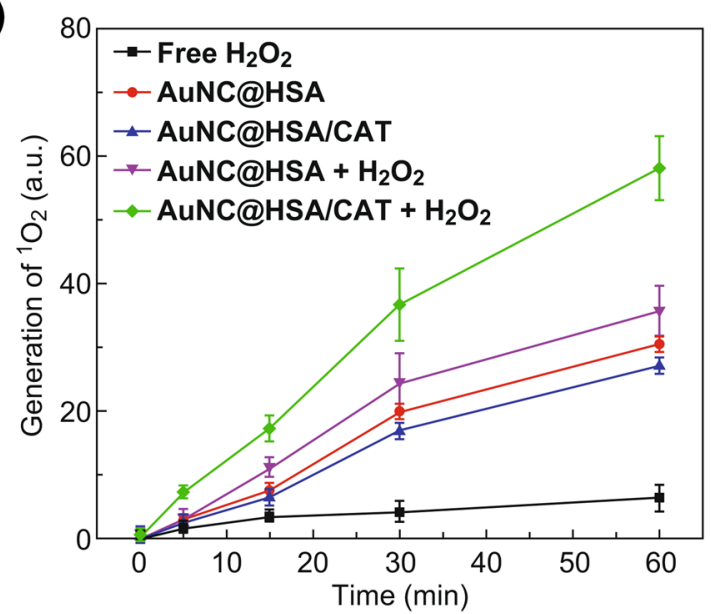

(e)

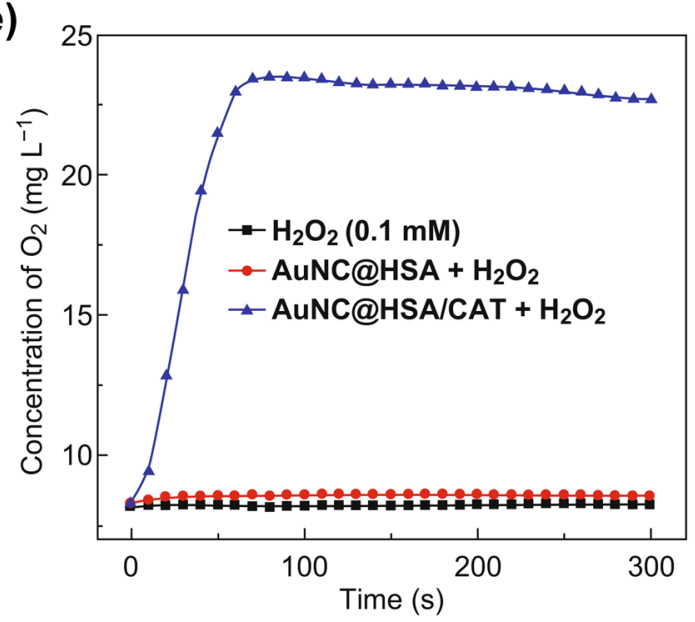

Fig. 4 a Schematic diagram of enzyme-like activity of AuNCs. b Through the catalase activity of AuNCs- $\mathrm{NH}_{2}$, a simple strategy of combining traditional PDT with self-supplying $\mathrm{O}_{2}$ leads to increase in ${ }^{1} \mathrm{O}_{2}$ and $\mathrm{O}_{2}^{\bullet-}$ generation. Adapted with permission from Ref. [32]. Copyright 2017 Wiley-VCH. c Schematic illustration of the synthesis of AuNC@HSA/CAT nanoparticles. d ${ }^{1} \mathrm{O}_{2}$ generation for AuNC@HSA or AuNC@ HSA/CAT with or without addition of $\mathrm{H}_{2} \mathrm{O}_{2}$. e $\mathrm{O}_{2}$ generation in $\mathrm{H}_{2} \mathrm{O}_{2}$ solutions (100 $\left.\mu \mathrm{M}\right)$ incubated with AuNC@HSA or AuNC@HSA/CAT. Adapted with permission from Ref. [33]. Copyright 2017 Springer

$\mathrm{H}_{2} \mathrm{O}_{2}$ catalysis in dark will ameliorate the hypoxia, alleviating tumor invasion and metastasis. In vitro and in vivo studies have shown that this system could treat tumors more effectively by synergistically enhancing PDT and
TME regulation (Fig. 5c, d). These studies not only enrich applications of Pt-based nanomaterials in cancer therapy, but also provide guidance for designing other nanosystems for cancer therapy. 
(a)

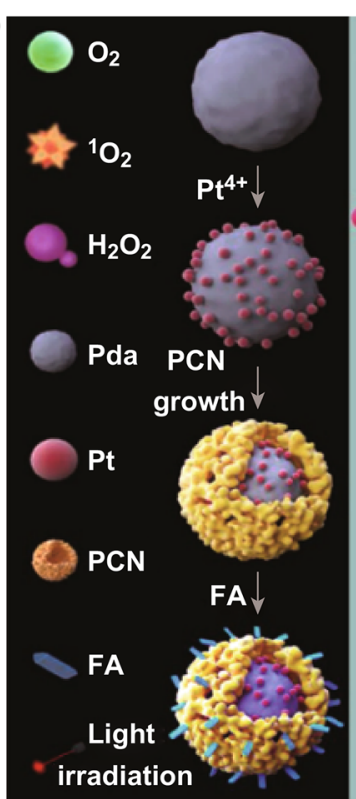

(b)

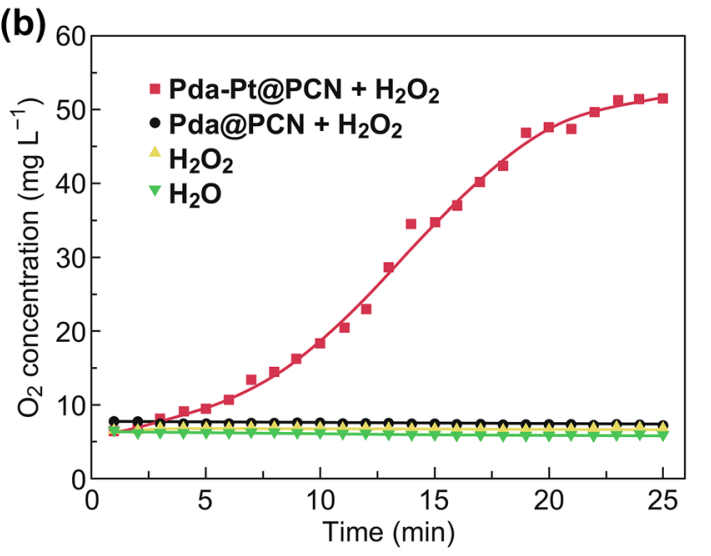

(c)

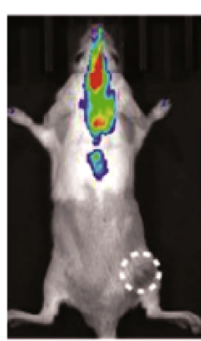

Pre-injection

$$
\begin{aligned}
2 \mathrm{H}_{2} \mathrm{O}_{2} & \stackrel{\mathrm{Pt}}{\longrightarrow} 2 \mathrm{H}_{2} \mathrm{O}+\mathrm{O}_{2} \\
\mathrm{O}_{2} & \stackrel{\text { Light }}{\stackrel{\mathrm{PCN}}{\longrightarrow}}{ }^{1} \mathrm{O}_{2}
\end{aligned}
$$
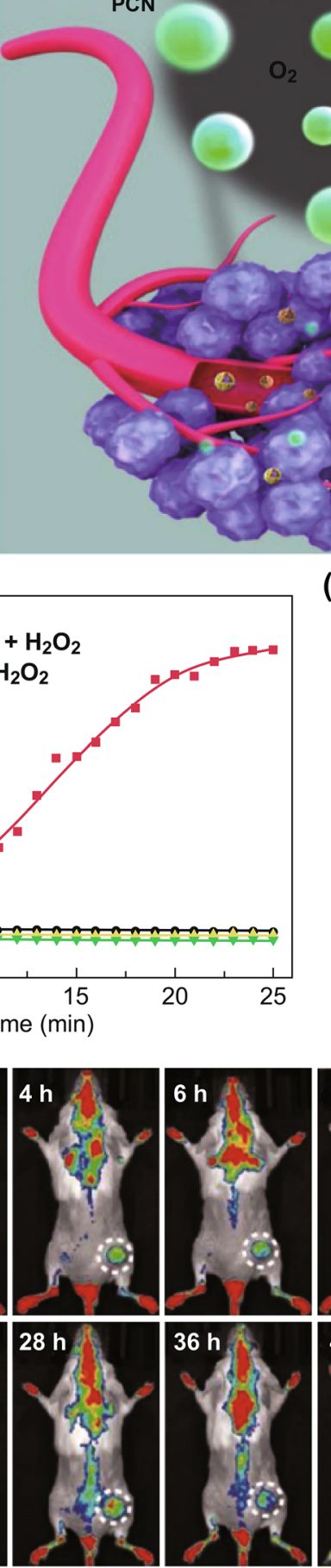
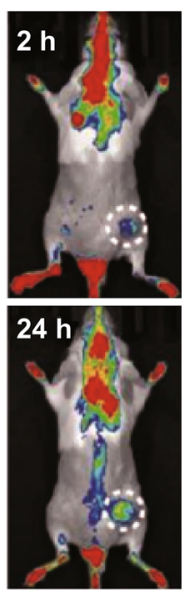

O

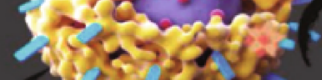

igy.rose 0

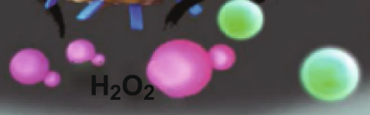

(

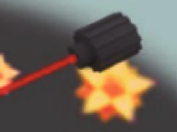

항
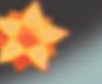

2.

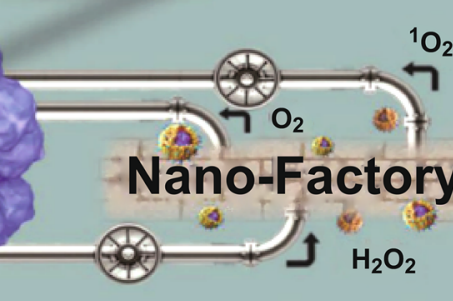

(d)
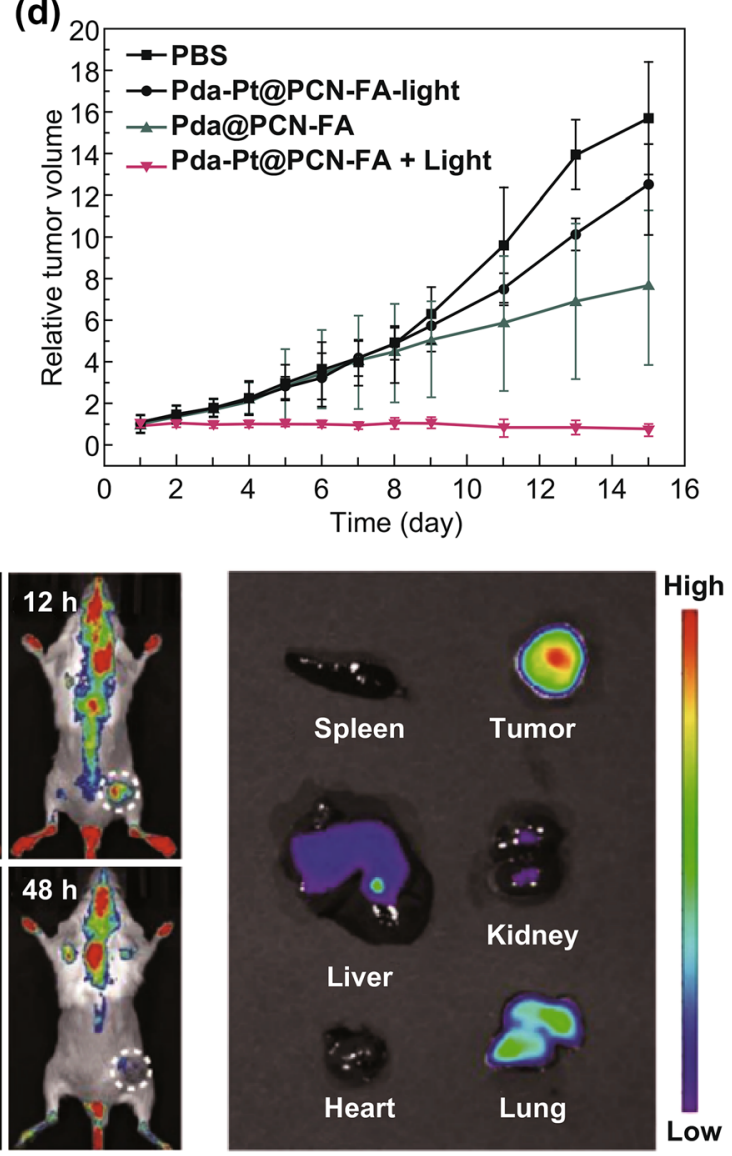

Fig. 5 a Schematic illustration of core-shell nanofactory for enhanced tumor therapy. Pda-Pt@PCN-FA converts $\mathrm{H}_{2} \mathrm{O}_{2}$ from tumors into $\mathrm{O}_{2}$ and ${ }^{1} \mathrm{O}_{2}$. b $\mathrm{O}_{2}$ generation of different groups. c In vivo fluorescence images of Pda-Pt @ PCN-FA at different time after intravenous injection. d Tumor growth volume curves of different treated mouse group. Adapted with permission from Ref. [35]. Copyright $2018 \mathrm{Wiley-VCH}$ 


\subsection{Fe-Based Materials}

In recent years, $\mathrm{Fe}$-based materials have received much attention in cancer treatment due to their high relaxation, excellent contrast enhancement, and biocompatibility. As a typical class of Fe-based materials, $\mathrm{Fe}_{2} \mathrm{O}_{3} / \mathrm{Fe}_{3} \mathrm{O}_{4}$-based materials have been used as magnetic resonance imaging (MRI) contrast agent and applied for magnetic hyperthermia in cancer treatment. In addition, Fenton reaction between $\mathrm{Fe}$ (II)/Fe(III) and $\mathrm{H}_{2} \mathrm{O}_{2}$ have been proved to be a direct ROS generation platform without light triggering [36]. Although Fe-based materials have been extensively studied for the detection of $\mathrm{H}_{2} \mathrm{O}_{2}$, their applications in PDT via $\mathrm{H}_{2} \mathrm{O}_{2}$ response have just appeared in recent years.

For example, Jiang's group [37] developed Fe(III)-doped two-dimensional (2D) $\mathrm{C}_{3} \mathrm{~N}_{4}$ nanosheets for MRI and antitumor PDT. As a new type of 2D semiconductor material, graphite $\mathrm{C}_{3} \mathrm{~N}_{4}\left(\mathrm{~g}-\mathrm{C}_{3} \mathrm{~N}_{4}\right)$ nanosheet can be regarded as $\mathrm{N}$-substituted graphite because of the six nitrogen lonepair electrons in its $\pi$-conjugated structure and can be used for complexing or doping metal ions for functionalization (Fig. 6a). In this paper, $\mathrm{C}_{3} \mathrm{~N}_{4}$ was doped with $\mathrm{Fe}$ (III), which resulted in excellent peroxidase-like catalytic performance. By catalyzing $\mathrm{H}_{2} \mathrm{O}_{2}$ to produce oxygen at the tumor site,

(a)

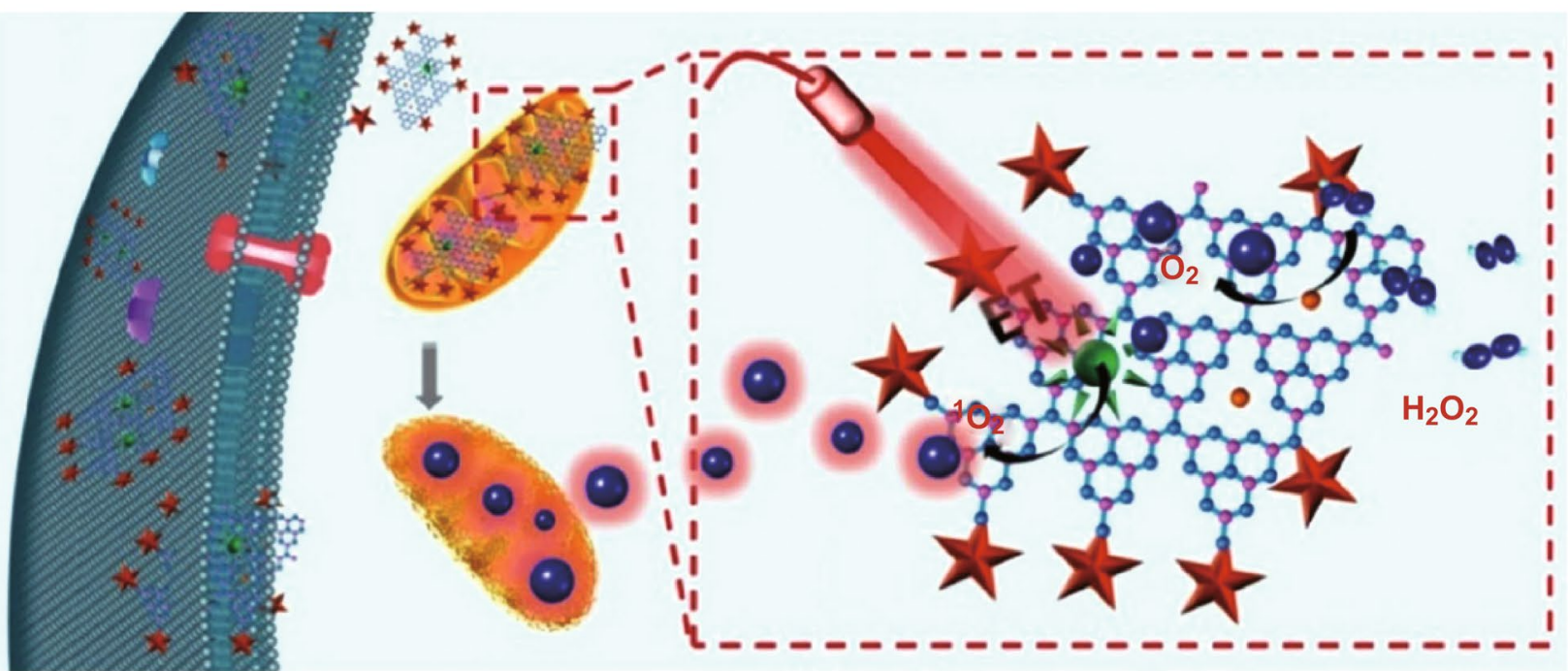

(b)

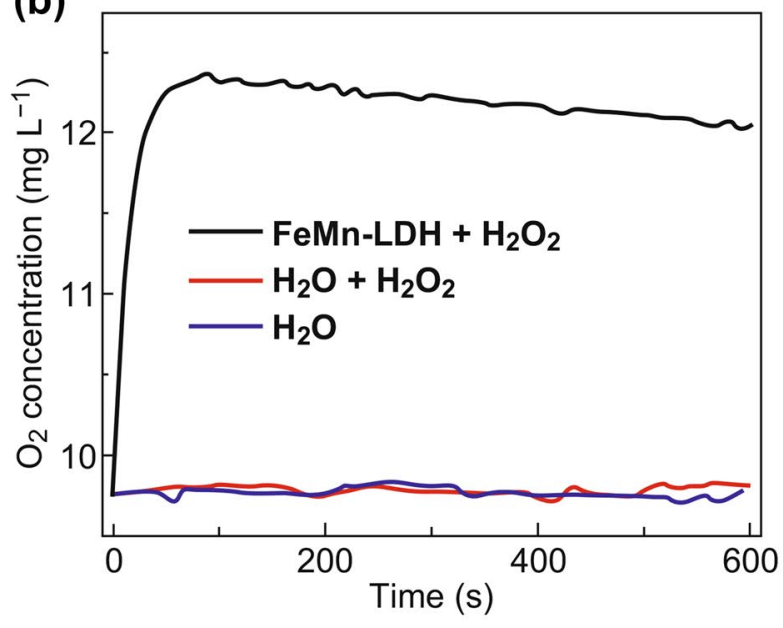

(c)
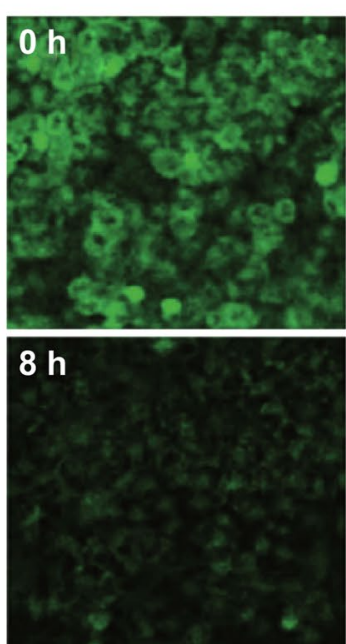

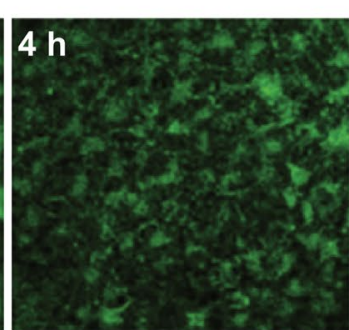

$24 \mathrm{~h}$

Fig. 6 a Schematic illustration of $\mathrm{C}_{3} \mathrm{~N}_{4}$-Fe-TPP NF/MB as theranostic nanocomposites for mitochondria-targeting $\mathrm{H}_{2} \mathrm{O}_{2}$-enhanced PDT. Adapted with permission from Ref. [37]. Copyright 2016 Wiley-VCH. b $\mathrm{O}_{2}$ was catalyzed by FeMn-LDH adding $\mathrm{H}_{2} \mathrm{O}_{2}(100 \mathrm{mM})$. c Evolution of $\mathrm{O}_{2}$ in HeLa cells incubated with $\mathrm{O}_{2}$ probe RDPP and FeMn-LDH $\left(100 \mathrm{mg} \mathrm{mL}^{-1}\right)$ at different time $(0,4,8$, and 24 h). Adapted with permission from Ref. [38]. Copyright 2018 Royal Society of Chemistry 
the tumor hypoxia can be overcame and the PDT efficiency can be improved. Furthermore, after loaded with PS methylene blue (MB) and conjugated with mitochondria-targeting moiety (4-carboxybutyl) triphenylphosphonium bromide (TPP), a mitochondria-targeting photodynamic agent had been formed, which could evolve $\mathrm{O}_{2}$ into ROS by catalytic decomposition of $\mathrm{H}_{2} \mathrm{O}_{2}$. In addition, the loaded $\mathrm{MB}$ led to excellent photocatalytic performance toward $\mathrm{O}_{2}$ to generate ${ }^{1} \mathrm{O}_{2}$, improving PDT efficiency. This development significantly overcame hypoxia in tumor tissue and broke the hypoxia limitation for PDT. Moreover, the ultra-high surface area of 2D nanosheets enhanced the PS loading capacity and could be used for effective interaction with tumor tissue for enhanced PDT efficiency.

Recently, Mn-Fe-layered double hydroxide (MnFe-LDH) nanosheets, new 2D nanomaterials, have been developed for $\mathrm{O}_{2}$-evolving phototherapy [38]. In general, LDH can release metal ions in response to the acidic microenvironment within the tumor, revealing its high contrast for MRI. However, the light absorption properties and biological catalytic activity of LDH has been neglected. It has been revealed that MnFe-LDH exhibited a broad NIR absorption spectrum due to small polaron absorption of oxygen defects. Moreover, the $\mathrm{MnFe}-\mathrm{LDH}$ aqueous dispersion not only exhibited a great photothermal effect, but also could generate a large amount of oxygen when $\mathrm{H}_{2} \mathrm{O}_{2}$ was added (Fig. 6b, c). Oxygen-sensitive fluorescence probes have been applied and confirmed that both $\mathrm{Mn}^{3+/ 4+}$ and $\mathrm{Fe}^{3+}$ present effective $\mathrm{H}_{2} \mathrm{O}_{2}$ catalytic properties in this $2 \mathrm{D}$ nanosheets. The catalase-like activity of MnFe-LDH nanosheets enabled the decomposition of endogenous $\mathrm{H}_{2} \mathrm{O}_{2}$ into $\mathrm{O}_{2}$; therefore, tumor hypoxia could be overcame and therapeutic efficacy of $\mathrm{O}_{2}$-dependent PDT could be enhanced under laser illumination.

Another work based on Fe-Fenton theory is reported by Lin's group [39]. In this work, the authors constructed FePtNP2 nanoplatform using iron oxide as nanocarriers to load cisplatin (IV) prodrug. Nanoparticles could be preferentially accumulated in the tumor site via magnetic field-mediated localization and monitored by MRI. Specifically, in TME, cisplatin can activate the expression of nicotinamide adenine dinucleotide phosphate (NADPH) oxidase (NOX), which can transport electrons so that the $\mathrm{O}_{2}$ molecule can accept donated electron to generate $\cdot \mathrm{O}_{2}^{-}$. Then, SOD catalyzes $\cdot \mathrm{O}_{2}^{-}$to form $\mathrm{H}_{2} \mathrm{O}_{2}$ which can be reacted with iron ions to improve Fenton-like reaction, resulting in highly toxic $\cdot \mathrm{OH}$ for enhanced PDT. In physiologically neutral or weakly acidic tumor environment, the Fe-Fenton reaction efficiency is relatively low. Even under ideal $\mathrm{pH}$ conditions, the $\mathrm{Fe}^{2+}$ catalyzed Fenton reaction has a low reaction rate $\left(\sim 63 \mathrm{M}^{-1} \mathrm{~s}^{-1}\right)$, which leads to slow ROS generation [40]. Therefore, it is highly desirable to develop nanoformulations with high catalytic activity and specificity in a weakly acidic TME.

\subsection{Cu-Based Materials}

Different from $\mathrm{Fe}^{2+}$-catalyzed Fenton reaction, the redoxactive cuprous ion $\left(\mathrm{Cu}^{+}\right)$-catalyzed Fenton-like reaction is more advantageous in terms of kinetics and energy. It has been reported that a $\mathrm{Cu}^{+}$catalyzed Fenton-like reaction can occur efficiently in weakly acidic and neutral media. Its highest reaction rate $\left(1 \times 10^{4} \mathrm{M}^{-1} \mathrm{~s}^{-1}\right)$ can reach $\sim 160$ times that of $\mathrm{Fe}^{2+}[41,42]$. Therefore, many works about $\mathrm{Cu}$-based $\mathrm{H}_{2} \mathrm{O}_{2}$-responsive materials have been reported. Considering that copper ions have a high coordination ability with sulfhydryl group-containing ligands, Liu's group produced novel copper-amino acid mercaptide nanoparticles named $\mathrm{Cu}-\mathrm{Cys}$ NPs (Fig. 7a) [43]. Once the Cu-Cys NPs are endocytosed into cancer cells, GSH associates with the $\mathrm{Cu}-\mathrm{Cys} \mathrm{NPs}$ and reduces $\mathrm{Cu}^{2+}$ to $\mathrm{Cu}^{+}$. Then, $\mathrm{Cu}^{+}$can react with $\mathrm{H}_{2} \mathrm{O}_{2}$ to generate $\mathrm{Cu}^{2+}$ and $\cdot \mathrm{OH}$ via the Fenton-like reaction, leading to DNA damage, protein inactivation, lipid peroxidation, and ultimately cell apoptosis (Fig. 7b). The in vivo experiment showed that tumor size could be effectively decreased after $\mathrm{Cu}$-Cys NPs treatment, with a higher tumor suppressing potency in vivo $(\sim 72.3 \%$ inhibition rate) than the chemotherapeutic drug DOX (only 17.1\% inhibition rate) (Fig. 7c, d). Besides, Cu-Cys NPs showed no significant damage on major organs, implying its great potential in cancer therapy with high specificity (Fig. 7e). Another work worth mentioning is reported by Jiang's group. They prepared novel tetrakis(4-carboxyphenyl)porphyrin (TCPP)-modified 2D nanoscale metal-organic frameworks (nMOFs), Cu-TCPP, which can generate ${ }^{1} \mathrm{O}_{2}$ by reacting with $\mathrm{H}_{2} \mathrm{O}_{2}$ and reduce the concentration of GSH in TME [44]. Cu-TCPP showed a novel ${ }^{1} \mathrm{O}_{2}$ generation mechanism. The TCPP can be peroxidized by $\mathrm{H}_{2} \mathrm{O}_{2}$ at acidic $\mathrm{pH}$ and can be further reduced to peroxyl radicals (ROO.) and a trace amount of $\mathrm{Cu}^{2+}$ ions. Then, ${ }^{1} \mathrm{O}_{2}$ can be produced in the spontaneous recombination reaction of ROO. In addition, the consumption of GSH into oxidized glutathione (GSSG) by the incorporated $\mathrm{Cu}^{2+}$ 
(a)

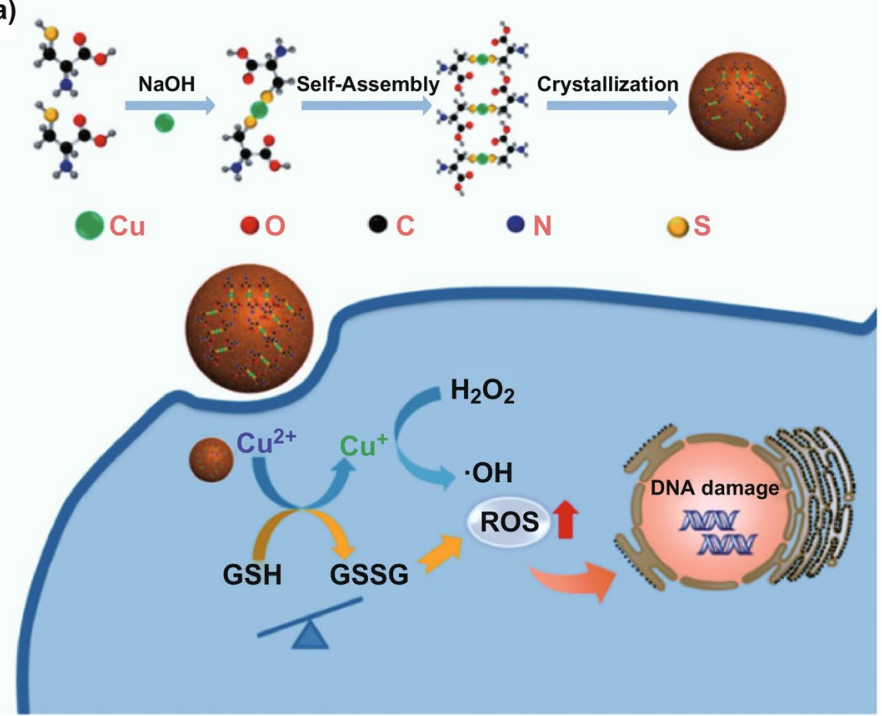

(b)

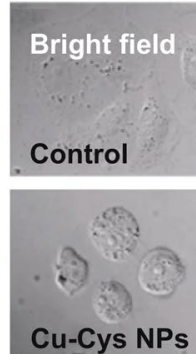

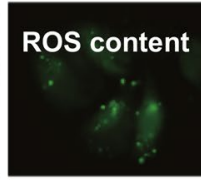

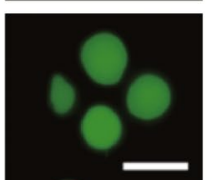

(c)

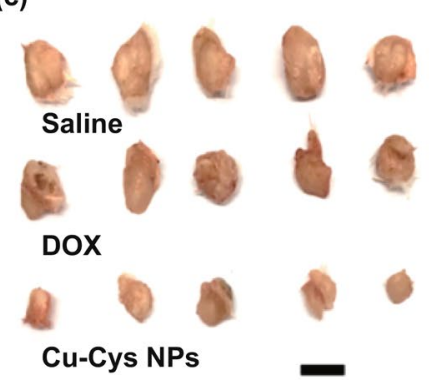

(d)
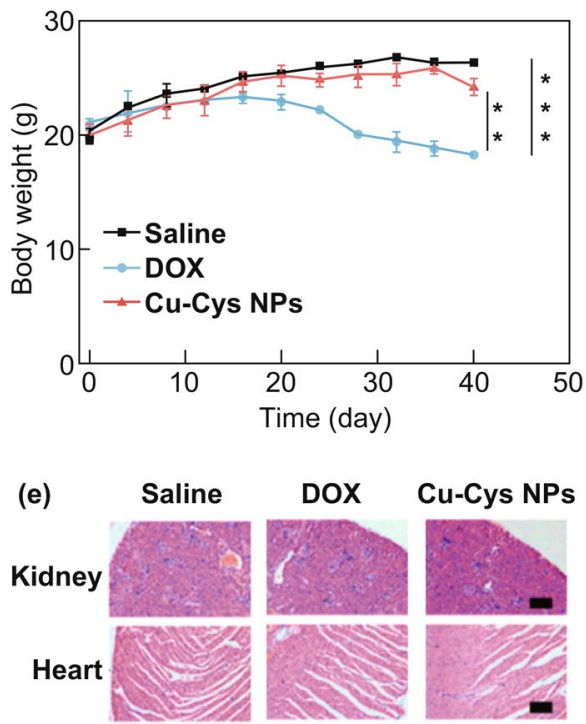

Cu-Cys NPs

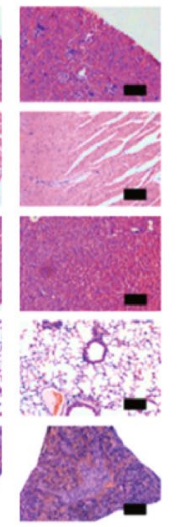

Fig. 7 a Schematic diagram of the synthesis and action mechanism of Cu-Cys NPs. b Detection of ROS in ADSCs and MCF-7R cells before and after $\mathrm{Cu}-\mathrm{Cys} \mathrm{NPs}$ treatment. $\mathbf{c}$ Photographs of tumors collected from the mice. d Changes in body weight of mice during treatment. e Histological analysis of the major organs after treatment. Adapted with permission from Ref. [43]. Copyright 2018 American Chemical Society

ions which could prevent it from effectively scavenging ${ }^{1} \mathrm{O}_{2}$ further increases the therapeutic efficiency. Different from previous strategies, the Russell mechanism has been utilized to produce ${ }^{1} \mathrm{O}_{2}$ directly in the presence of trace metal ions. At the same time, biohydroperoxides can be produced directly by the peroxidation of ROS, which provides an alternative to oxygen-dependent photodynamic agents.

\subsection{Ce-Based Materials}

As a rare-earth element, cerium has attracted much attention because of its strong redox ability and relatively high earth abundance. CeOx NPs have many advantages, such as low toxicity, catalytic activity, and adjustable absorption spectra. The interconversion between trivalent and tetravalent oxidation states plays an important role in biomedical and drug delivery. CeOx NPs show different enzyme mimics based on the ratio of $\mathrm{Ce}^{3+}$ to $\mathrm{Ce}^{4+}$. In addition, some studies indicated that $\mathrm{CeOx}$ NPs oxidase mimics could cause DNA damage, which made them cell killers at low $\mathrm{pH}$. Therefore, Ce-based nanomaterials with the ability of catalase mimics and high tumor selectivity may be a more promising approach to achieve highly efficient PDT for future clinical treatment [45-47].

For example, Yang's group developed a hollow-structured biophotocatalyst nanomaterials named UCNPs@ $\mathrm{mCeOx}$ by coating mesoporous cerium oxide (mCeOx) on upconverting nanoparticles (UCNPs, $\mathrm{NaGdF}_{4}: \mathrm{Yb}, \mathrm{Tm} @$ $\mathrm{NaGdF}_{4}$ ) [48]. The highly efficient and stable luminescent core-shell NPs can continuously convert $980 \mathrm{~nm}$ NIR laser into ultraviolet light, thereby exciting cerium oxide for PDT. The $\mathrm{H}_{2} \mathrm{O}_{2}$-responsive materials achieve sustained self-sufficiency of $\mathrm{O}_{2}$ during PDT, overcoming the obstacles of tumor 


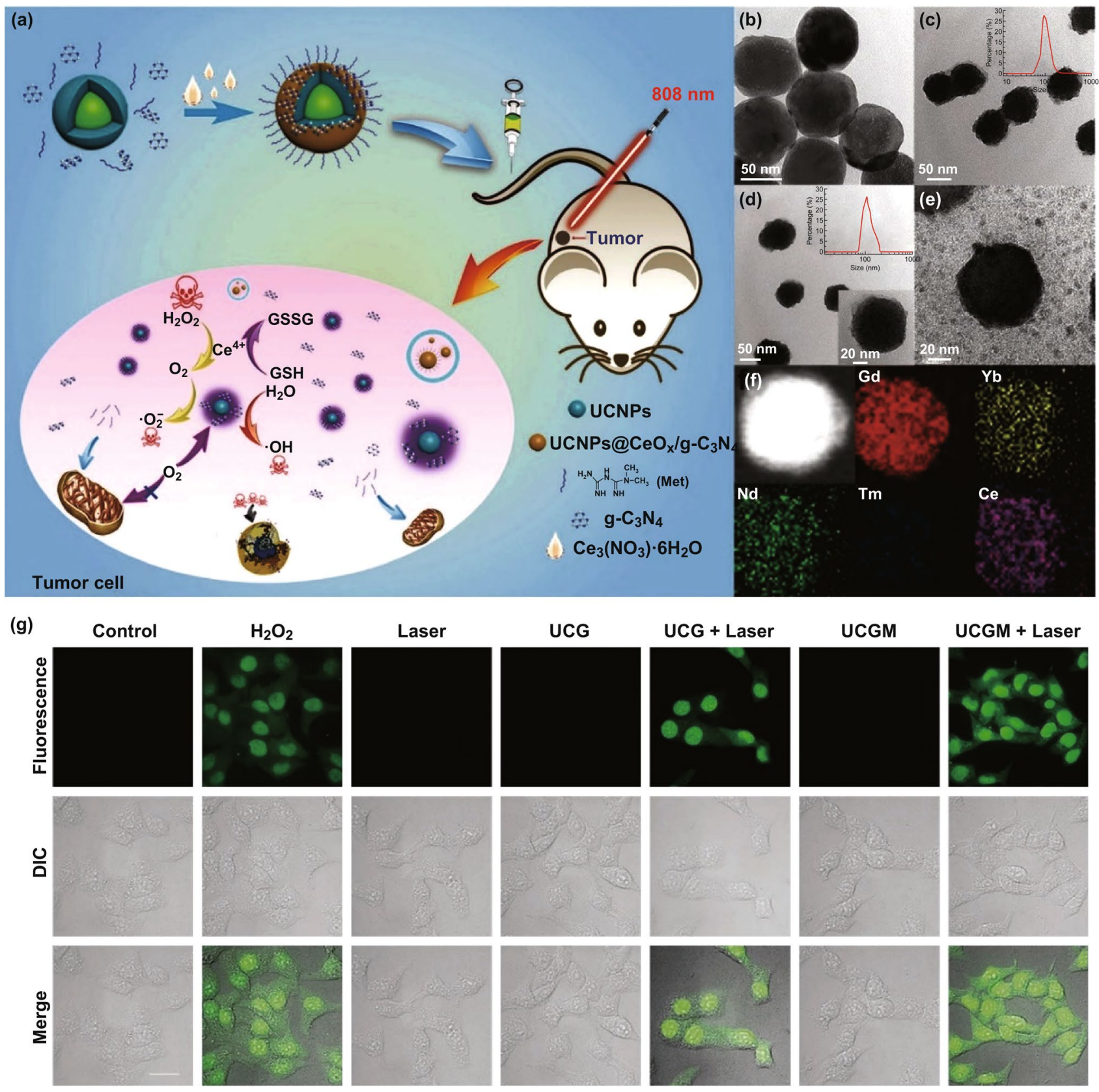

Fig. 8 a Schematic diagram of the synthesis and action mechanism of UCNPs@CeOx/g- $\mathrm{C}_{3} \mathrm{~N}_{4}$. b TEM image of NaGdF4:Yb, Tm@ $\mathrm{NaGdF}_{4}: \mathrm{Yb}, \mathrm{Nd}$ NPs. $\mathbf{c}$ TEM image of UCG NPs and the DLS curve of UCG NPs. $\mathbf{d}$ TEM images of UCGM NPs. e TEM images of UCGM NPs treated with $\mathrm{H}_{2} \mathrm{O}_{2}$ for $4 \mathrm{~h}$ under acidic condition ( $\mathrm{pH}$ 6.5). f The EDS element mapping of UCGM NPs. g CLSM images of ROS generated in HepG2 cells with different treatment methods using H2DCFDA as indicator. Scale bar: $10 \mu \mathrm{m}$. Adapted with permission from Ref. [49]. Copyright 2019 Wiley-VCH

hypoxia under near-infrared irradiation. In addition, inorganic UCNPs@mCeOx with high photostability is compared to conventional organic photosensitizers. Moreover, the huge hollow structure effectively loads the chemotherapeutic drug DOX, achieving synergistic PDT and chemotherapy.
Ding's group produced a multifunctional nanocluster bomb (UCGM nanoparticles) composed of UCNP NPs, CeOx, graphite- $\mathrm{C}_{3} \mathrm{~N}_{4}\left(\mathrm{~g}-\mathrm{C}_{3} \mathrm{~N}_{4}\right) \mathrm{NPs}$ and metformin (Met) (Fig. 8a-f) [49]. $\mathrm{CeOx}$ could catalyze $\mathrm{H}_{2} \mathrm{O}_{2}$ into $\mathrm{O}_{2}$ to improve the oxygenation of TME. Meanwhile, Met can 
act on the mitochondria to inhibit the respiration of tumor cells to further increase $\mathrm{O}_{2}$ level. Under $808 \mathrm{~nm}$ laser irradiation, UCGM NPs have excellent photothermal capability, which could effectively convert near-infrared light into ultraviolet light, thus activating $\mathrm{g}-\mathrm{C}_{3} \mathrm{~N}_{4} \mathrm{NPs}$ to produce ROS in tumor site and cause the tumor cell death. Further more, the UCGM NPs show excellent upconversion performance, magnetic resonance imaging and computed tomography imaging, making them potential imagingguided drug delivery systems for cancer therapy (Fig. 8g). Great efficiency in combined PDT/PTT was achieved based on UCGM NPs.

In summary, a class of multifunctional nanomaterials with self-supplementing $\mathrm{O}_{2}$, NIR excitation, multimode imaging, and efficient ROS generation performance were synthesized for efficient PTT/PDT.

\section{Organic Materials for $\mathrm{H}_{2} \mathrm{O}_{2}$-Responsive Phototherapy}

The common design for $\mathrm{H}_{2} \mathrm{O}_{2}$-responsive organic materials for enhanced cancer PDT is to immobilize organic PSs with $\mathrm{H}_{2} \mathrm{O}_{2}$-responsive moieties. $\mathrm{H}_{2} \mathrm{O}_{2}$-responsive moieties are functional groups with specific bonds such as boronic acid group [50], sulfide bond (-s-) [51], selenium bond (-Se-) [52], and tellurium bond (-Te-) [53]. Herein, we will provide an overview of current researches on $\mathrm{H}_{2} \mathrm{O}_{2}$-responsive drug delivery systems for enhanced PDT based on these functional groups.

\subsection{Aryl Boronic Ester-Based Materials}

Boric acid is usually considered to be low toxic for humans and can be used in biomedical science. It is well-known that the esters of the aryl boronic acids can be cleaved by $\mathrm{H}_{2} \mathrm{O}_{2}$ and can be used in $\mathrm{H}_{2} \mathrm{O}_{2}$-activated fluorescent probes. Previous works have proved that phenyl boronic acid can be responsive to endogenous $\mathrm{H}_{2} \mathrm{O}_{2}$ to form a phenol in pathological conditions due to the oxidative stress caused by high level of $\mathrm{H}_{2} \mathrm{O}_{2}$ in cancer cells [54]. This reactivity provides a biologically compatible method for detecting endogenous $\mathrm{H}_{2} \mathrm{O}_{2}$.

Kuang and co-workers are pioneers in the design of nitrogen mustard prodrugs based on $\mathrm{H}_{2} \mathrm{O}_{2}$-activated aryl boronic ester [55], which could be activated by high level of $\mathrm{H}_{2} \mathrm{O}_{2}$ in cancer cells (Fig. 9a). These agents consist of two functional domains: the $\mathrm{H}_{2} \mathrm{O}_{2}$ acceptor moiety and the effector for cytotoxicity. A significantly increased cytotoxic potency can be achieved by releasing nitrogen mustard when triggering the aryl boronic ester with $\mathrm{H}_{2} \mathrm{O}_{2}$ (Fig. 9b). Their selectivity and antitumor activity is evaluated by comparing their effect on normal cells and cancer cells (Fig. 9c). It has been reported that both directly deliver ROS-producing agents to tumor tissues and inhibit the antioxidant system through destroying the redox balance in cancer cells which could remarkably enhance the ROS-mediated cancer cell killing efficiency. Based on that, Noh J.'s group synthesized [4-(1,3,2-dioxaborinan-2-yl)benzyl ((5-methyl-2-styryl-1,3-dioxan-5-yl) methyl) carbonate] (QCA) by coupling a quinone methide (QM)-generating moiety with ROS-generating cinnamaldehyde (Fig. 9d). Meanwhile, boronate was conjugated to cinnamaldehyde via a carbonate linker to achieve $\mathrm{H}_{2} \mathrm{O}_{2}$-responsive drug release [56]. The obtained product, QCA, can not only elevate intracellular ROS level through the reaction between cinnamaldehyde and endogenous $\mathrm{H}_{2} \mathrm{O}_{2}$, but also produce an antioxidant inhibitor quinone methide $(\mathrm{QM})$ and triggering cell apoptosis. The in vitro and in vivo studies showed that cinnamaldehydemediated ROS production and the QM-induced oxidative stress elevation could result in enhanced apoptotic cell death (Fig. 9e, f). Herein, it is feasible to construct $\mathrm{H}_{2} \mathrm{O}_{2}$-responsive systems through a boron-based covalent bond to promote the intracellular generation of ROS and potentially to result in enhanced PDT. To the best of our knowledge, there is a growing trend referring to the research of $\mathrm{H}_{2} \mathrm{O}_{2}$-responsive materials based on aryl boronic groups. Aryl boronic acid and aryl boronic ester functional groups provide a promising way for enhanced PDT based on $\mathrm{H}_{2} \mathrm{O}_{2}$-response.

\subsection{Sixth Main Group Elements-Based Organic Materials}

The sixth main group elements (oxygen group elements) mainly refer to oxygen $(\mathrm{O})$, sulfur $(\mathrm{S})$, selenium $(\mathrm{Se})$, and tellurium (Te), which are all electronegative, easily losing their outermost electrons, and being oxidized by $\mathrm{H}_{2} \mathrm{O}_{2}$. In particular, the bond energies of $\mathrm{C}-\mathrm{Se}, \mathrm{Se}-\mathrm{Se}, \mathrm{C}-\mathrm{S}, \mathrm{S}-\mathrm{S}$, $\mathrm{C}-\mathrm{Te}$, and $\mathrm{Te}-\mathrm{Te}$ are below $300 \mathrm{~kJ} \mathrm{~mol}^{-1}$, especially for 
(a)<smiles>CC1(C)OB(c2ccc(C[N+](C)(CCCl)CCCl)cc2)OC1(C)C</smiles><smiles>C[N+](CCCl)(CCCl)Cc1ccc(B(O)O)cc1</smiles><smiles>CN1CCOB(c2ccc(C[N+](C)(C)CCO)cc2)OCCN(Cc2ccc(B3OC(C)(C)C(C)(C)O3)cc2)CC1</smiles>

(c)

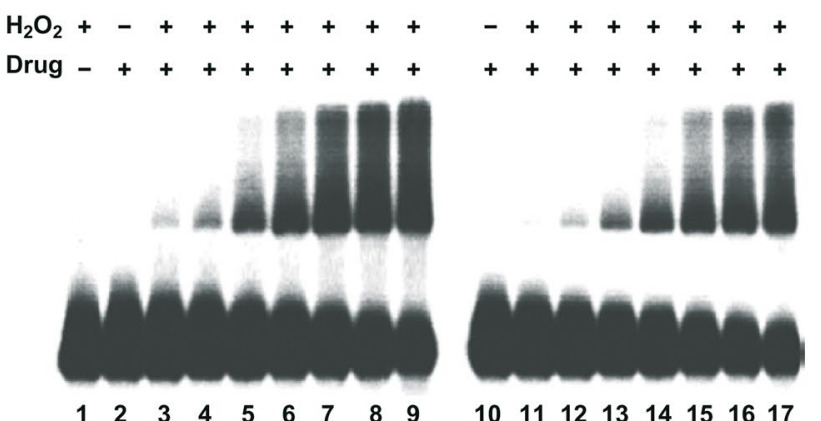

(b)

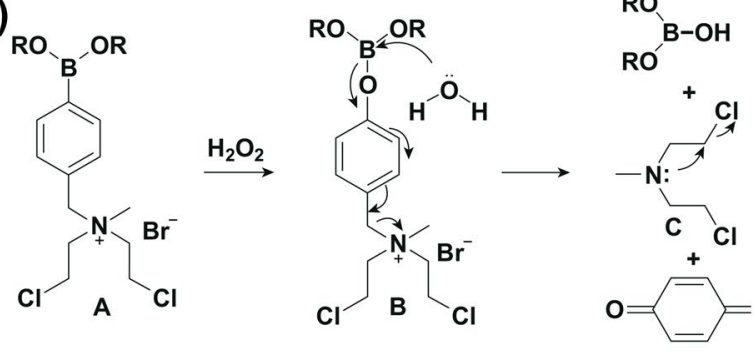

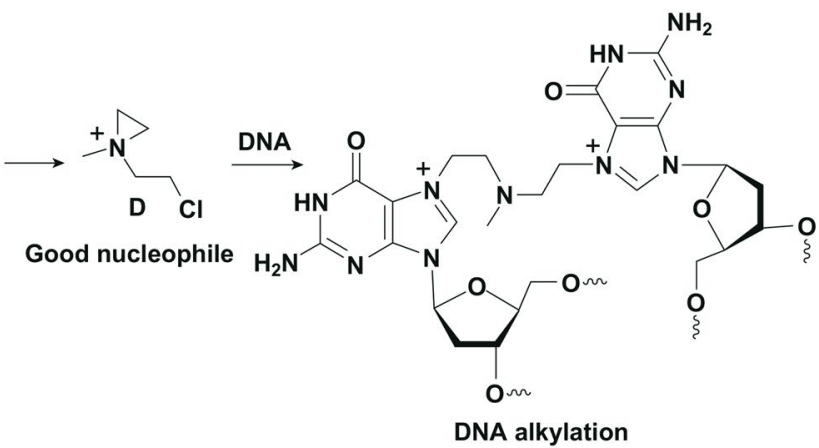

(e)

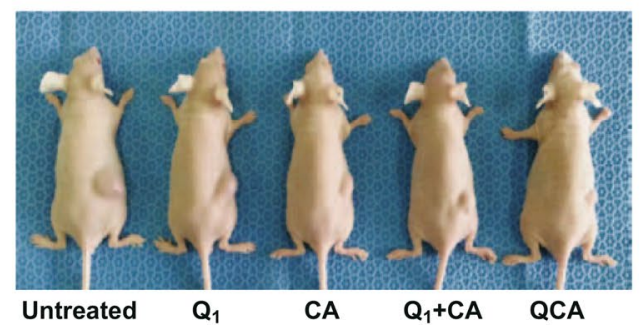

(d)

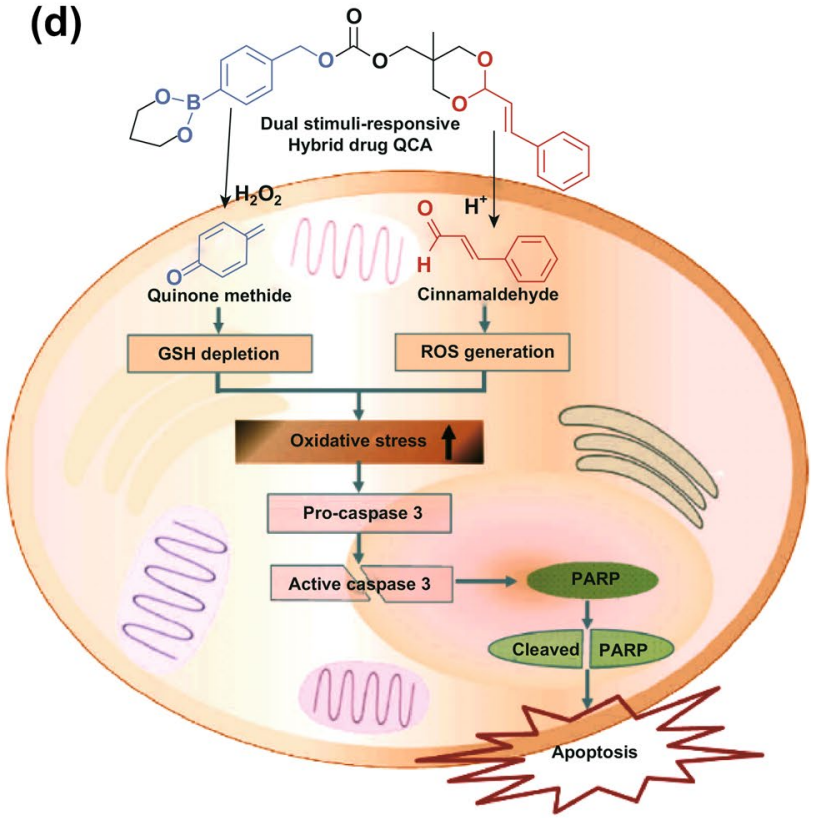

(f)

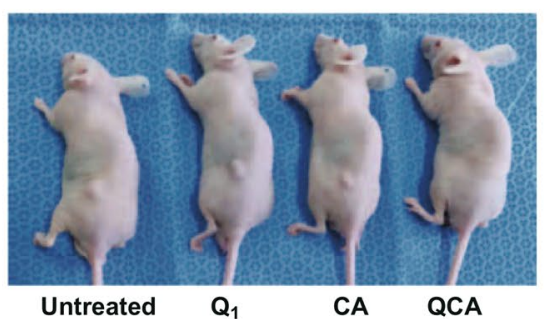

Fig. 9 a Compounds 1-4. b Formation of interchain crosslinks (ICL) induced by 1 and 2 during $\mathrm{H}_{2} \mathrm{O}_{2}$ activation. b Release of nitrogen mustard from compound 1 upon treatment with $\mathrm{H}_{2} \mathrm{O}_{2}$. c The concentration dependence of compounds 1 and 2 on DNA cross-linking formation upon $\mathrm{H}_{2} \mathrm{O}_{2}$ activation. Lane 1 without drug; lanes 2-9 with drug 1: lane 2, without $\mathrm{H}_{2} \mathrm{O}_{2}$ (cross-linking yield $0 \%$ ); lane $3,50 \mu \mathrm{M} \mathrm{H} \mathrm{O}_{2}+100 \mu \mathrm{M}$ 1 (2.2\%); lane 4, $100 \mu \mathrm{M} \mathrm{H}_{2} \mathrm{O}_{2}+200 \mu \mathrm{M} \mathrm{1(5 \% );} \mathrm{lane} \mathrm{5,} 250 \mu \mathrm{M} \mathrm{H}_{2} \mathrm{O}_{2}+500 \mu \mathrm{M} 1$ (11\%); lane 6, $500 \mu \mathrm{M} \mathrm{H}_{2} \mathrm{O}_{2}+1.0 \mathrm{mM} 1$ (18\%); lane 7, $1.0 \mathrm{mM} \mathrm{H}_{2} \mathrm{O}_{2}+2.0 \mathrm{mM} 1$ (28\%); lane 8, $1.5 \mathrm{mM} \mathrm{H}_{2} \mathrm{O}_{2}+3.0 \mathrm{mM} 1$ (36\%); lane 9, $2.0 \mathrm{mM} \mathrm{H}_{2} \mathrm{O}_{2}+4.0 \mathrm{mM} 1$ (42\%); lanes10-17 with drug 2: lane 10, without $\mathrm{H}_{2} \mathrm{O}_{2}(0 \%)$; lane $11,50 \mu \mathrm{M} \mathrm{H}_{2} \mathrm{O}_{2}+100 \mu \mathrm{M} 2(2.0 \%)$; lane $12,100 \mu \mathrm{M} \mathrm{H}_{2} \mathrm{O}_{2}+200 \mu \mathrm{M} 2(4 \%) ;$ lane $13,250 \mu \mathrm{M} \mathrm{H} \mathrm{O}_{2}+500 \mu \mathrm{M}$ 2 (11\%); lane 14, $500 \mu \mathrm{M} \mathrm{H}_{2} \mathrm{O}_{2}+1.0 \mathrm{mM} 2$ (17\%); lane 15, $1.0 \mathrm{mM} \mathrm{H}_{2} \mathrm{O}_{2}+2.0 \mathrm{mM} 2$ (27\%); lane 16, $1.5 \mathrm{mM} \mathrm{H}_{2} \mathrm{O}_{2}+3.0 \mathrm{mM} 2(35 \%)$; lane 17, $2.0 \mathrm{mM} \mathrm{H}_{2} \mathrm{O}_{2}+4.0 \mathrm{mM} 2$ (43\%). Adapted with permission from Ref. [55]. Copyright 2011 American Chemical Society. d QCA is activated and degraded by $\mathrm{H}_{2} \mathrm{O}_{2}$ and acidic $\mathrm{pH}$, leading to amplified oxidative stress and driving cells to undergo apoptotic death. e Representative images of mice bearing SW620 tumor xenografts. f Representative images of mice bearing DU145 tumor xenografts. Adapted with permission from Ref. [56]. Copyright 2015 Nature Publishing Group

S-S $\left(264 \mathrm{~kJ} \mathrm{~mol}^{-1}\right)$, Se-Se $\left(193 \mathrm{~kJ} \mathrm{~mol}^{-1}\right)$, and Te-Te $\left(138 \mathrm{~kJ} \mathrm{~mol}^{-1}\right)$, making the sixth main group elements-based agents more sensitive to $\mathrm{H}_{2} \mathrm{O}_{2}$ [57]. Sulfur is an essential element in organisms as well as an important component of 
protein in human body [58]. Selenium is the essential mineral nutrient in human body, which cannot be synthesized by ourselves but only rely on external supply. Researches show that selenium is very important for improving immunity and cancer prevention for its antioxidation property [59]. Below selenium is tellurium in the periodic table; Te-based agents are expected to be more sensitive to $\mathrm{H}_{2} \mathrm{O}_{2}$ than Se-based ones due to their higher electronegativity [60]. Meanwhile, tellurium-containing compounds have been used to develop new glutathione peroxidase (GPX) by imitating the natural antioxidant enzyme to protect cells from oxidative damage [61]. Moreover, studies show that organotellurium-containing compounds are less toxic than organoselenium-containing compounds [53]. These results inspire researchers to exploit the sixth main group elementsbased agents for stimuli-responsive drug delivery systems. Herein, $\mathrm{H}_{2} \mathrm{O}_{2}$-responsive materials based on the sixth main group elements for enhanced PDT are discussed in detail (Table 1).

\subsubsection{Oxygen-Based Materials}

Oxygen-based agents which are responsive to $\mathrm{H}_{2} \mathrm{O}_{2}$ typically contain functional groups such as aryl oxalate ester (AOE) and orthoesters. When exposed to very low concentration $(\sim 250 \mathrm{nM})$ of $\mathrm{H}_{2} \mathrm{O}_{2}$, AOEs are selectively cleaved at the oxalate group and undergo an autocatalytic mechanism, which would decompose into carbon dioxide rapidly. Orthoesters

Table $1 \mathrm{H}_{2} \mathrm{O}_{2}$-responsive bonds based on the sixth main group elements

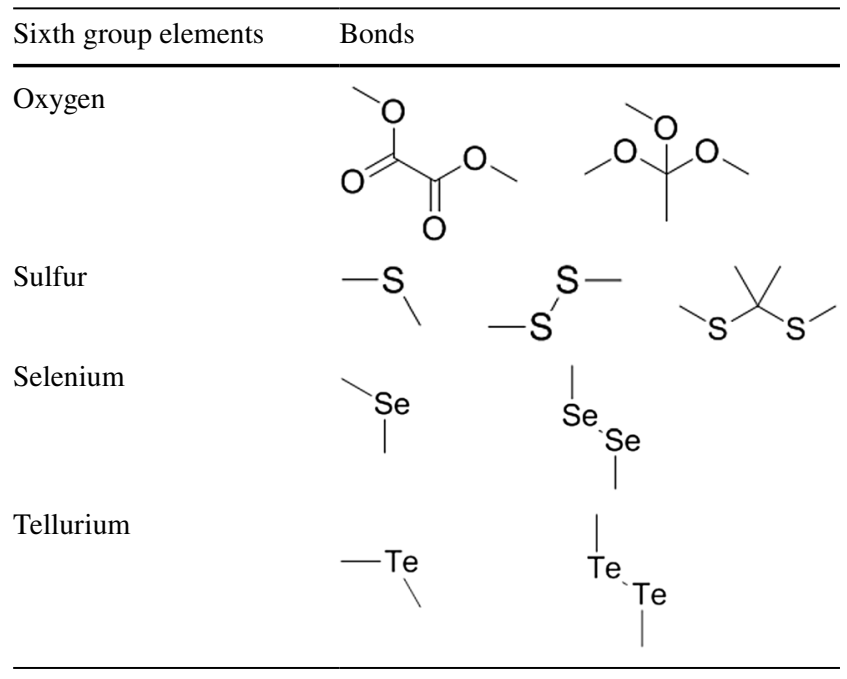

are compounds formed by the substitution of three hydroxy groups of alkoxy acids with alkoxy groups. Their general formula is $\mathrm{RC}\left(\mathrm{OR}^{\prime}\right) 3$, where $\mathrm{R}$ represents hydrogen or an alkyl group and R' refers to an alkyl group. Orthoesters are extremely sensitive to mild acid and low concentrations of $\mathrm{H}_{2} \mathrm{O}_{2}$ and can be degraded by oxidation with $\mathrm{H}_{2} \mathrm{O}_{2}$.

Lee and co-workers successfully synthesized a biodegradable peroxalate copolymer named HPOX (Fig. 10a) [62]. This copolymer eligible to release active hydroxybenzyl alcohol (HBA) by a hydrolysis reaction in the presence of $\mathrm{H}_{2} \mathrm{O}_{2}$, accompanied by the formation of carbon dioxide $\left(\mathrm{CO}_{2}\right)$. Meanwhile, the intramolecular oxalate structure would be degraded into oxalic acid under the same conditions. After this work, they also reported a series of HPOX-based systems for the diagnosis and remedy of oxidative stress-associated diseases. These special nanoparticles could be loaded with fluorescent dyes, PSs or drugs, demonstrating their potential for bioimaging, phototherapy and drug delivery.

Further research about $\mathrm{H}_{2} \mathrm{O}_{2}$-responsive systems based on AOE functional groups for enhanced PDT was reported by Lin's group. A new C-TBD nanoparticle was formulated by co-encapsulation of bis[2,4,5-trichloro-6-(pentyloxycarbonyl) phenyl] oxalate (CPPO) and a specially designed AIE PS TPEBT-DC (TBD) [63]. Considering that chemiluminescence is the luminescence typically produced by the release of energy through a chemical reaction between $\mathrm{H}_{2} \mathrm{O}_{2}$ and a high energy compound, it is a convenient technology with more clinical potential than bioluminescence and traditional fluorescence imaging since it does not require additional modifications. At the same time, the higher concentration of $\mathrm{H}_{2} \mathrm{O}_{2}$ in TME confers chemiluminescence good tumor selectivity. When CPPOTBD is exposed to $\mathrm{H}_{2} \mathrm{O}_{2}$, the reaction between the aryl oxalate ester group in $\mathrm{CPPO}$ and $\mathrm{H}_{2} \mathrm{O}_{2}$ produces 1,2-dioxetanedione diketone. If the energy levels of the highest occupied molecular orbitals (HOMO) of TBD and the lowest unoccupied molecular orbitals (LUMO) of the intermediate are match, 1,2-dioxetanedione can directly stimulate TBD to produce ${ }^{1} \mathrm{O}_{2}$ (Fig. 10b). In vivo experiments have shown that tumor imaging and therapeutic efficiency can be further improved when b-phenylethyl thiocyanate (FEITC, $\mathrm{H}_{2} \mathrm{O}_{2}$-enhanced agent) is introduced to increase the concentration of $\mathrm{H}_{2} \mathrm{O}_{2}$ in tumor (Fig. 10c, d). The novelty of this work is that it does not rely on external light sources, but far-infrared/near-infrared (FR/NIR) luminescence induced by aggregation can be used for accurate tumor imaging in vivo. These results prove that chemiluminescence imaging-guided PDT can be a promising noninvasive 
(a)

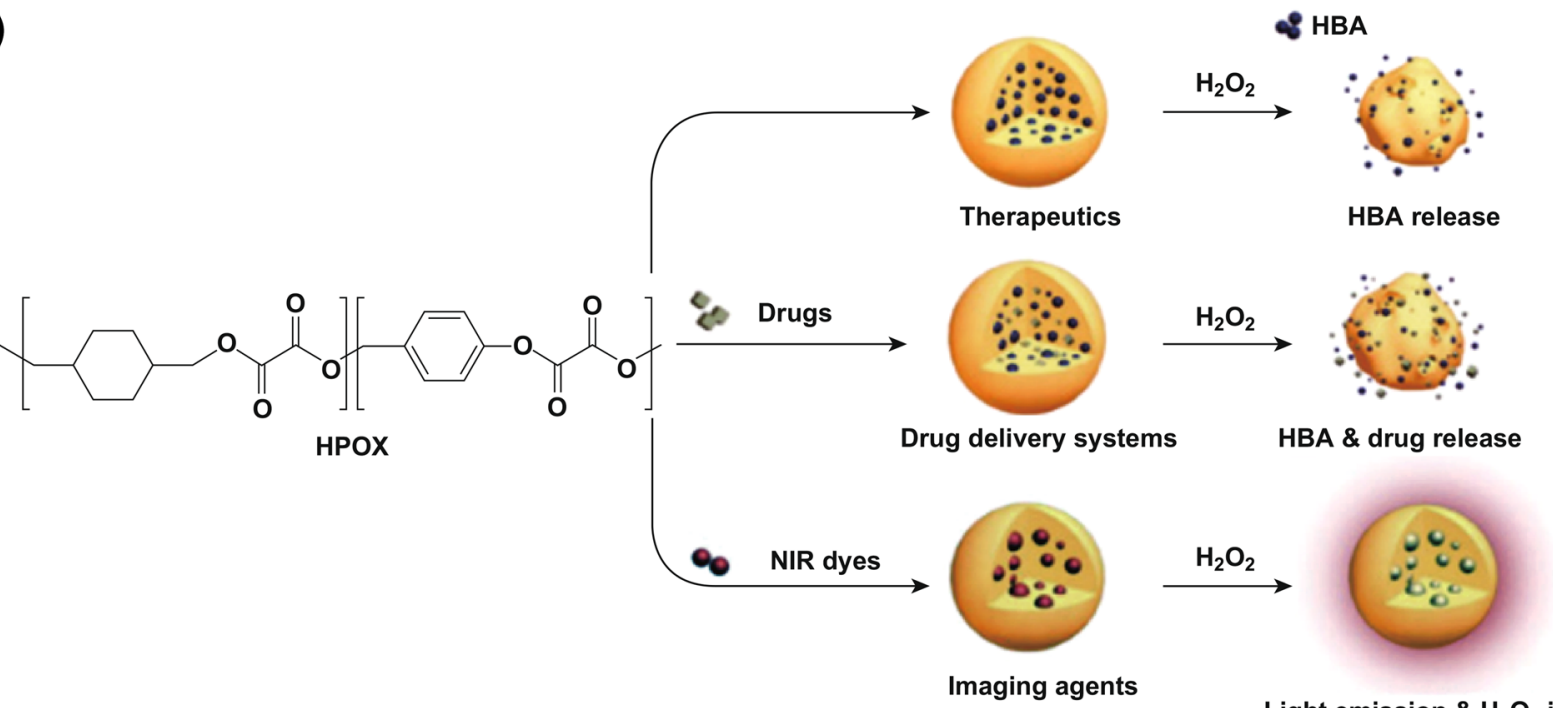

Light emission \& $\mathrm{H}_{2} \mathrm{O}_{2}$ imaging

(b)

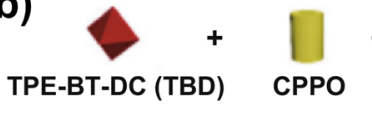<smiles>COc1ccc(C(=C(c2ccccc2)c2ccc(C3=CC=C(c4ccc(C(=C(C#N)C#N)c5ccccc5)cc4)C34N=N[SH]=N4)cc2)c2ccc(OC)cc2)cc1</smiles><smiles>COC(=O)c1c(Cl)cc(Cl)c(Cl)c1OC(=O)Oc1c(Cl)cc(Cl)c(Cl)c1C(=O)OCCO</smiles>

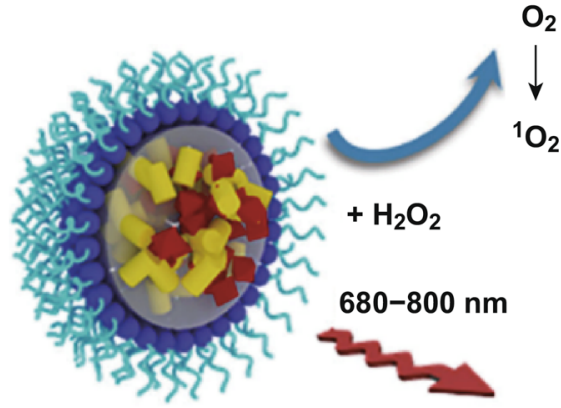

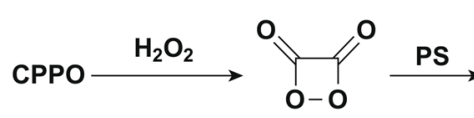

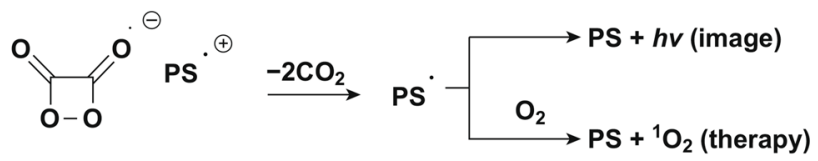

(c)
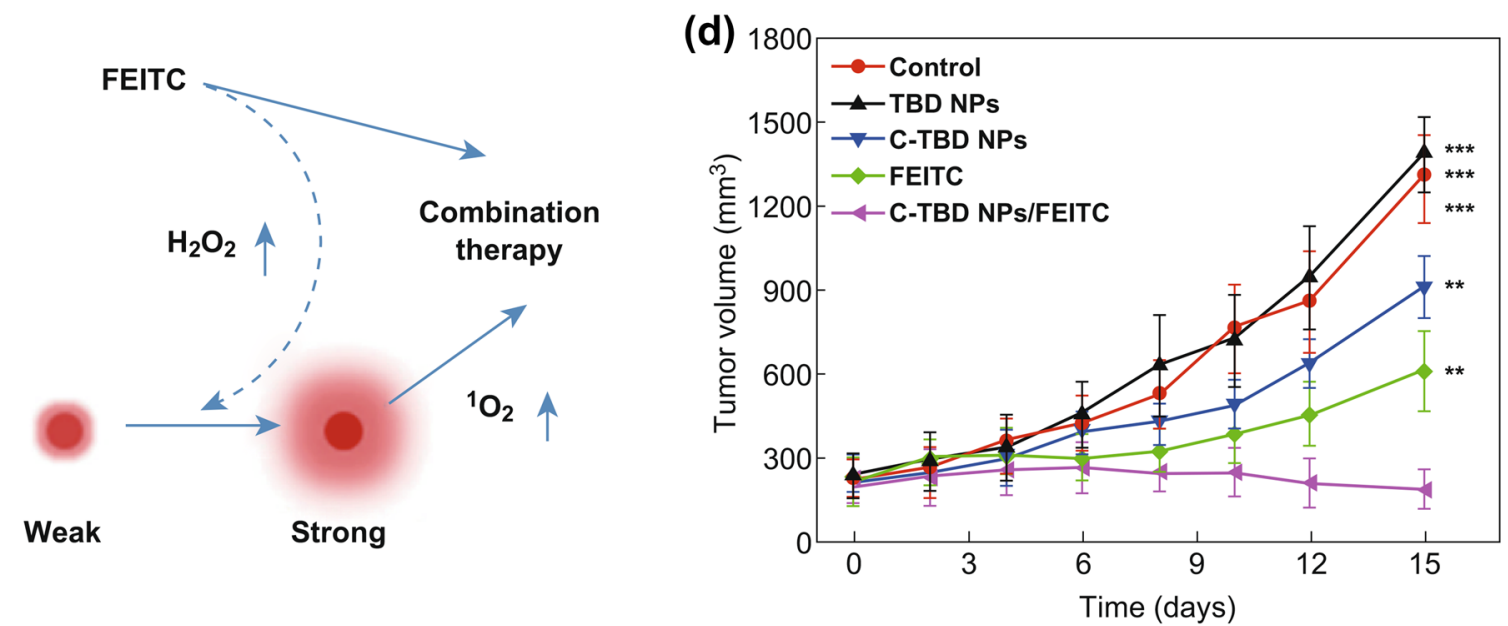

Fig. 10 a Multifunctional $\mathrm{H}_{2} \mathrm{O}_{2}$-activatable nanoparticles for bioimaging and therapy. Adapted with permission from Ref. [62]. Copyright 2013 Elsevier Ltd. b The preparation of C-TBD NPs and illustration of the principle for chemiluminescence and ${ }^{1} \mathrm{O}_{2}$ generation of C-TBD NPs in the presence of $\mathrm{H}_{2} \mathrm{O}_{2}$. c Schematic diagram of the hypothetical mechanism of C-TBD NPs and FEITC combination therapy. $\mathbf{d}$ Tumor growth curves with different therapies. Adapted with permission from Ref. [63]. Copyright 2017 Elsevier Ltd 
tool in cancer theranostics. Similar organic nanoparticles based on oxalate functional groups provide new ways to enhance PDT based on $\mathrm{H}_{2} \mathrm{O}_{2}$-responsive drug delivery systems.

\subsubsection{Sulfur-Based Materials}

According to the previous studies, compounds containing sulfide bond, especially thioethers or thiols, are usually used to react with $\mathrm{H}_{2} \mathrm{O}_{2}$. Thioethers are a group of compounds with the general formula R-S-R which undergo phase transition from hydrophobic to hydrophilic under ROS conditions, and thioether-based compounds have attracted much attention in stimuli-responsive drug delivery systems because thioethers could be oxidized into sulfones when exposed to $\mathrm{H}_{2} \mathrm{O}_{2}$. In addition, thiols are a class of nonaromatic organic sulfur compounds that contain thiol functional groups, which are usually applied as carbonyl protecting groups. In particular, thioketal bonds can be broken under oxidative condition. In recent years, large numbers of researchers started to focus on sulfide bond-based systems applied to $\mathrm{H}_{2} \mathrm{O}_{2}$-responsive drug delivery systems because of their unique oxidation properties. Based on this, the applications of $\mathrm{H}_{2} \mathrm{O}_{2}$-responsive drug delivery platforms based on sulfide bond in PDT have also been well reported.

Liu and co-workers used thioether as a linker to form the novel polymer micelles HPG-2S-SN38 [64], which was synthesized by conjugating hydrophilic hyperbranched polyglycerol (HPG) with 7-ethyl-10-hydroxycamptothecin (SN38), a hydrophobic antitumor drug. Cinnamaldehyde (CA) was then encapsulated into micelles to induce ROS production (Fig. 11a). Three typical cancer cell lines, MCF7, Hela, and HN-4 were used to study the anticancer effect of HPG-2S-SN38. After entering into cancer cells, the HPG2S-SN38 micelles were oxidized by oxidation of thioethers in the presence of $\mathrm{H}_{2} \mathrm{O}_{2}$, resulting in rapid hydrolysis of the phenolic esters in the structure of micelles, thus releasing CA and SN38 rapidly, resulting in an $\mathrm{H}_{2} \mathrm{O}_{2}$ concentration correlated synergistic antitumor effect. The evaluation of the cytotoxicity of HPG-2S-SN38 normal cells (L929 cells) ensures that $\mathrm{H}_{2} \mathrm{O}_{2}$ is the main pathway that triggers the oxidation of disulfide bonds and degrades HPG-2S-SN38, finally leading to cell apoptosis (Fig. 11b). This study demonstrates that $\mathrm{H}_{2} \mathrm{O}_{2}$-responsive polymer micelles constructed by sulfur-based bonds can enhance cell apoptosis through ROS production. For further improvement, it must be mentioned here that Yin's group applied thioketal to construct a gene delivery system combined with PDT for tumor therapy [65]. ROS-degradable nanocomplexes (TK-PEI/ DNA NCs) were successfully designed through thioketalcrosslinked polyethyleneimine (TK-PEI). After being coated with hyaluronic acid (HA), which was modified with pheophytin a (Pha) and co-delivered with a PS and p53 gene, TK-PEI/DNA NCs had colloidal stability (Fig. 11c). Upon intratumoral administration, NCs entered cancer cells via HA-assisted CD44 targeting, and then short-time visible light irradiation $\left(661 \mathrm{~nm}, 5 \mathrm{~m} \mathrm{Wcm}^{-2}, 8 \mathrm{~min}\right)$ produced non-lethal levels of ROS to facilitate the endosomal escape of NCs via the photo-chemical internalization (PCI) effect, and simultaneously promote the intracellular DNA release by degrading the TK-PEI. After successful transfection to produce p53 protein, long-term visible light irradiation $\left(661 \mathrm{~nm}, 5 \mathrm{~m} \mathrm{Wcm}^{-2}, 30 \mathrm{~min}\right)$ is generated for the process that internal light induces PSs to produce PDT effects. In this report, the size of TK-PEI/DNA NC changed significantly after $\mathrm{H}_{2} \mathrm{O}_{2}$ treatment, confirming that $\mathrm{H}_{2} \mathrm{O}_{2}$ induced cleavage of the thioketal crosslinker to degrade TK-PEI and dissociate TK-PEI/DNA NCs. It should be noted that among various ROS types, TK-PEI showed high sensitivity to superoxide and peroxide. These results clearly demonstrate that these block copolymer micelles are capable of drug-releasing when exposed to either oxidative $\left(\mathrm{H}_{2} \mathrm{O}_{2}\right)$ or reductive (GSH) environment in vitro. At the same time, they can enhance PDT through multi-responsive release and multi-model collaboration.

\subsubsection{Selenium-Based Materials}

The Spector's group first reported the antioxidant activity of selenium-based groups in 1989. In 1994, Iwaoka and Tomoda proposed a mechanism for the high sensitivity of diselenide bond to $\mathrm{H}_{2} \mathrm{O}_{2}$. When diselenoether was reacted with $\mathrm{H}_{2} \mathrm{O}_{2}$, the selenium ether rapidly catalyzed $\mathrm{H}_{2} \mathrm{O}_{2}$ into water and finally combined with hydroxide ions to form selenol [66]. Since then, a large number of researchers have put their efforts on the studies related to selenium-based groups due to their good activity in either oxidizing or reducing environment. When it comes to biological applications, selenium-containing compounds are well-known as antioxidants for its GPX activity. Meanwhile, selenium-based groups can be responsive to different external stimuli such as 
(a)

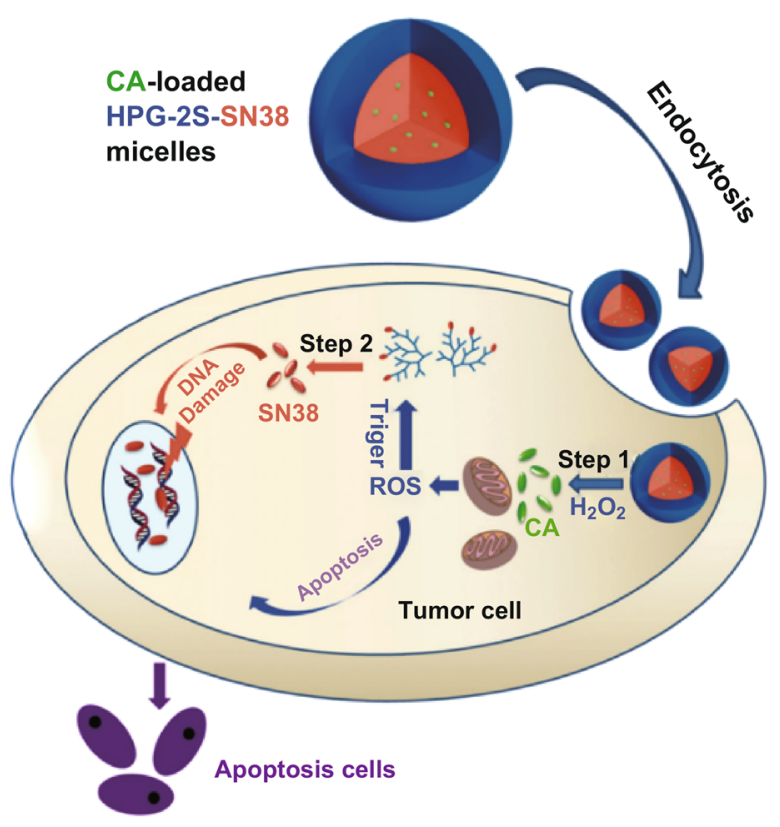

(b)
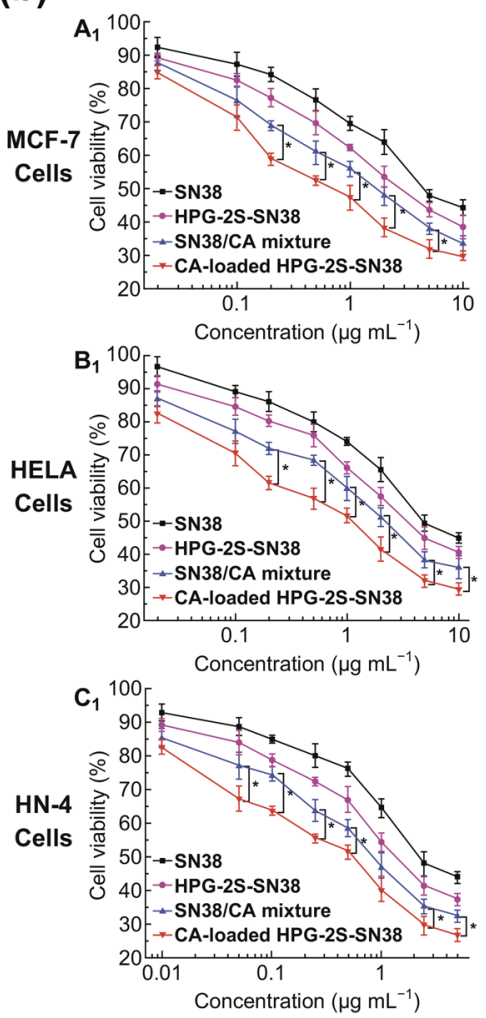
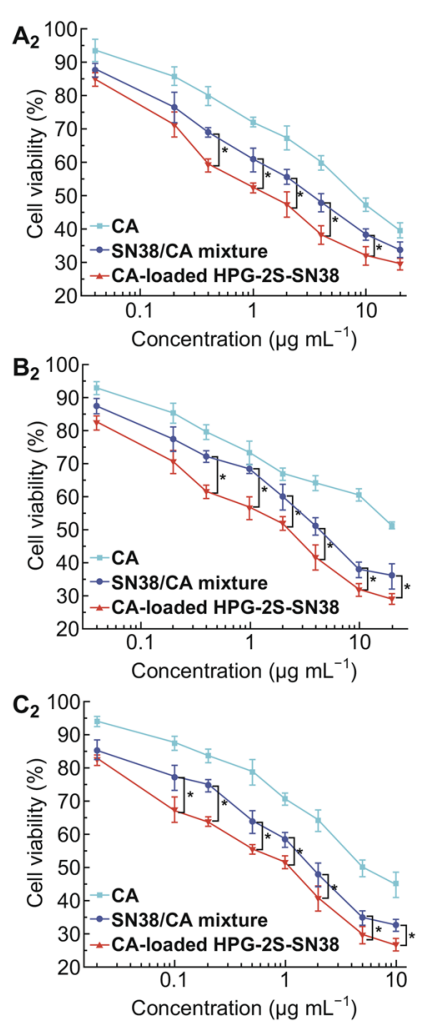

(c)
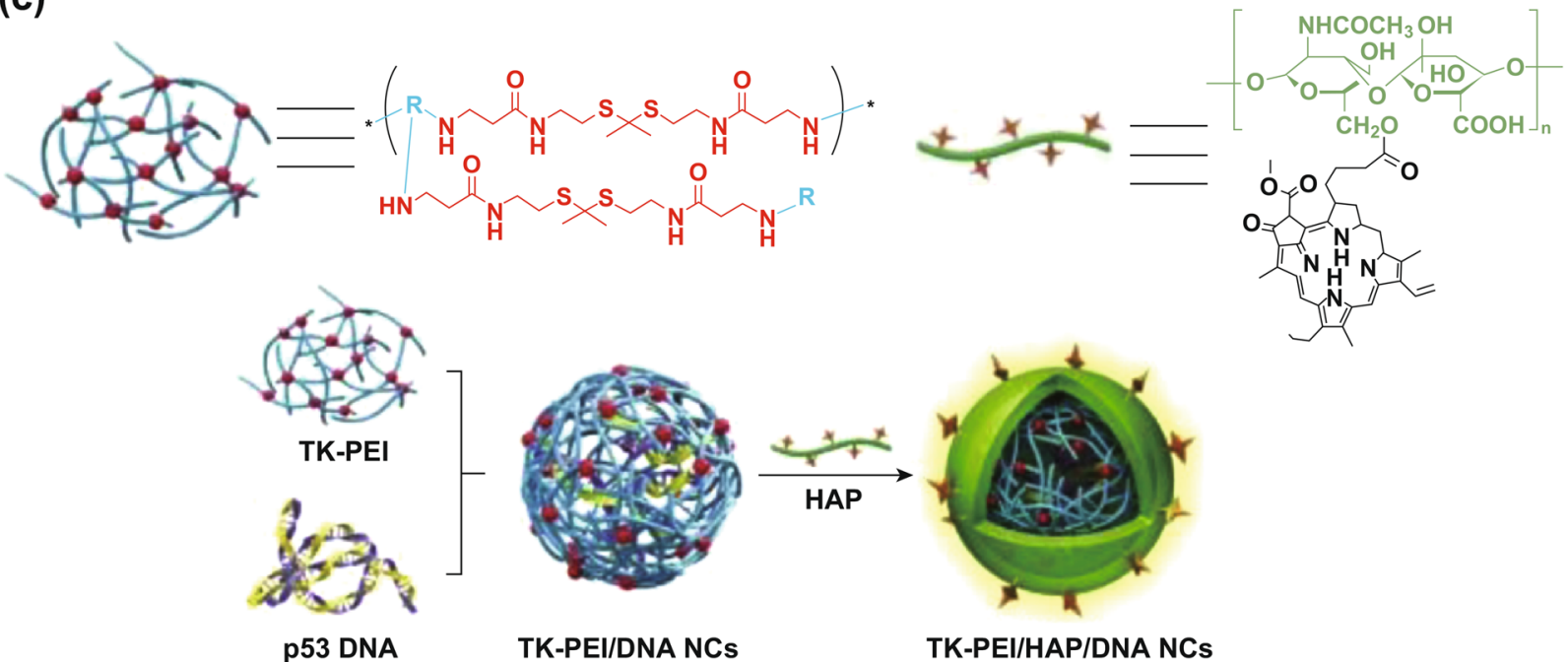

TK-PEI/HAP/DNA NCs

Fig. 11 a Schematic diagram of the mechanism of apoptosis induced by CA-loaded HPG-2S-SN38 nanomicelles. b Cell viability was (A1, A2) MCF-7 cells, (B1, B2) HeLa cells and $(\mathrm{C} 1, \mathrm{C} 2) \mathrm{HN}-4$ cells were treated with CA, SN38, HPG-2S-SN38 micelles after $48 \mathrm{~h}$, physical mixture of SN38 CA and CA-loaded HPG-2S-SN38 micelles were at various SN38 (A1, B1, C1) and CA (A2, B2, C2) concentrations. Adapted with permission from Ref. [64]. Copyright 2015 The Royal Society of Chemistry. c Schematic illustration of light-assisted p53 gene delivery and PDT for cooperative anticancer therapy. Adapted with permission from Ref. [65]. Copyright 2018 Elsevier Ltd

$\mathrm{pH}$, light, radical, temperature, reductants and oxidants, thus having been widely used in stimuli-responsive drug delivery systems. Among these stimuli, $\mathrm{H}_{2} \mathrm{O}_{2}$-responsive drug delivery platforms based on selenium have been developed for enhancing tumor PDT recently. 
(a)

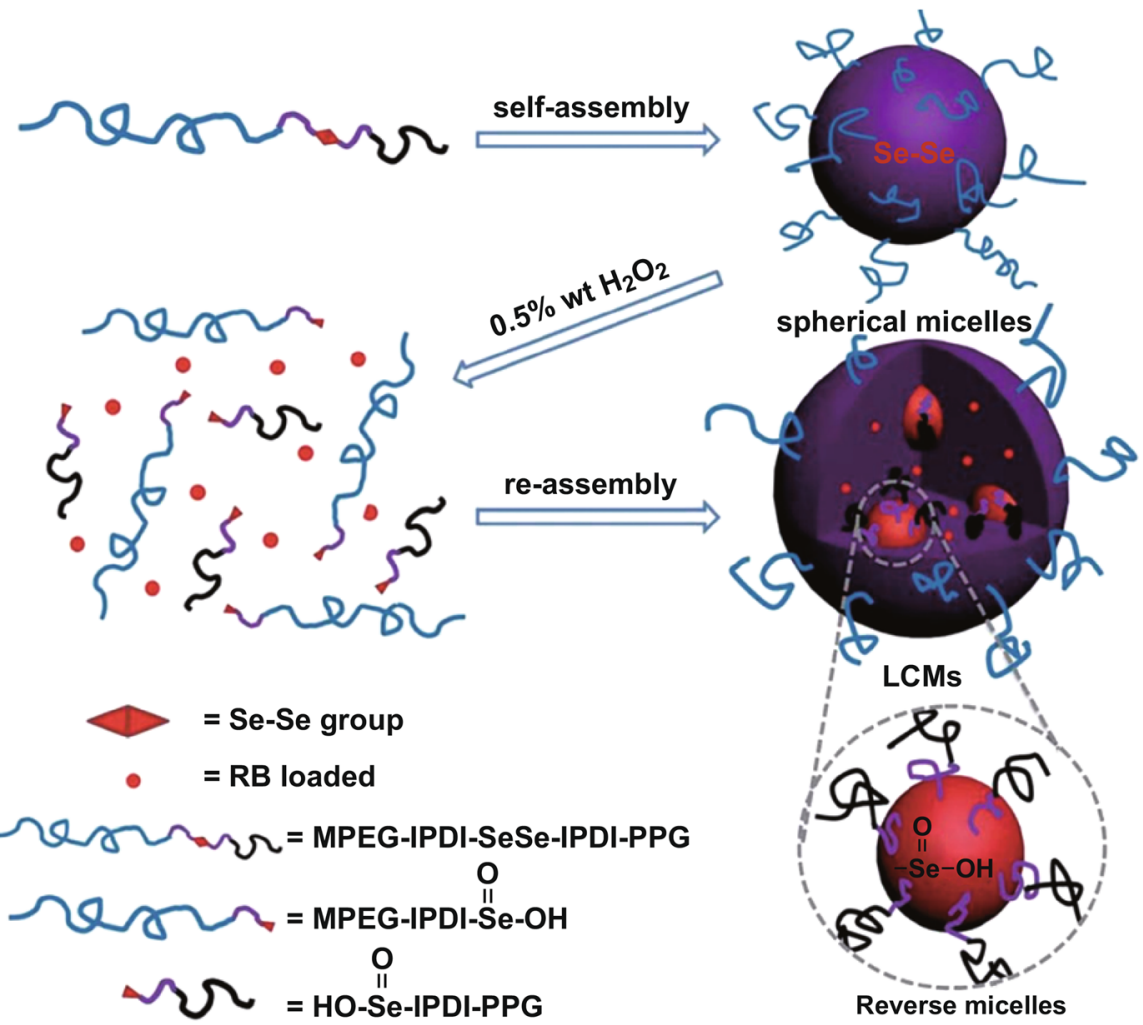

(b)

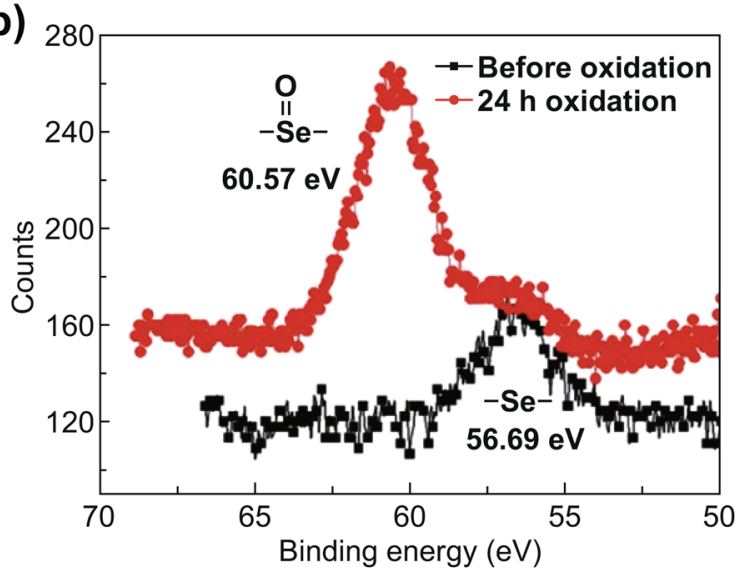

(c)

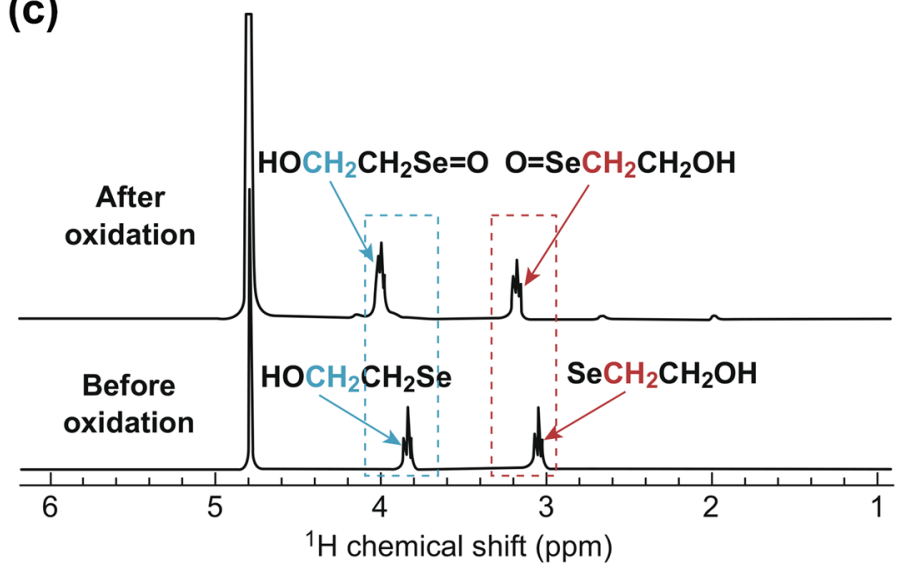

Fig. 12 a Schematic of the oxidation-responsive morphological transformation of MPEG-IPDI-Se-Se-IPDI-PPG micelles. b XPS analysis of the model compound $\mathrm{HOCH}_{2} \mathrm{CH}_{2} \mathrm{SeSeCH}_{2} \mathrm{CH}_{2} \mathrm{OH}$ before and after oxidation in $0.5 \mathrm{wt} \% \mathrm{H}_{2} \mathrm{O}_{2}$ solution. c ${ }^{1} \mathrm{H}-\mathrm{NMR}$ spectra of the model compound $\mathrm{HOCH}_{2} \mathrm{CH}_{2} \mathrm{SeSeCH}_{2} \mathrm{CH}_{2} \mathrm{OH}$ before (up) and after oxidation (down) in $0.5 \mathrm{wt} \% \mathrm{H}_{2} \mathrm{O}_{2}$ solution. Adapted with permission from Ref. [67]. Copyright 2013 The Royal Society of Chemistry

Sun and co-workers have developed a variety of selenium-based polymers through orderly coupling reactions, such as MPEG-IPDI-Se-Se-IPDI-PPG (Fig. 12a) [67] and an amphiphilic triblock polymer called Se-Se-tri-ABP [68]. They are oxidation-responsive and can undergo morphological transformation when exposed to $0.5 \mathrm{wt} \% \mathrm{H}_{2} \mathrm{O}_{2}$.
The authors used these selenium-based polymers to load cargos, and the effective release of cargo in the $\mathrm{H}_{2} \mathrm{O}_{2}$ environment verified its great potential in stimuli-responsive drug delivery. Due to the similar properties and functions of these polymers, we selected one of the most representative researches for a detailed discussion. Amphiphilic block 
(a)

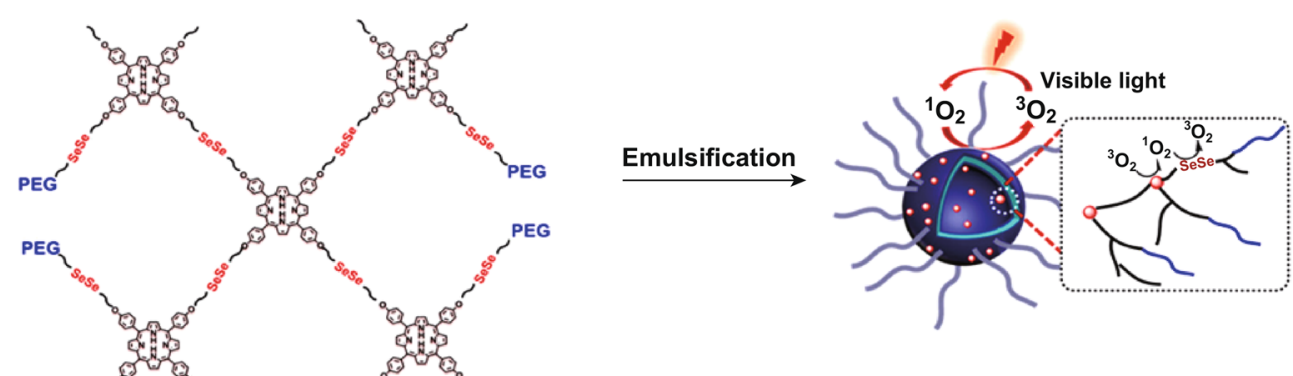

(b)

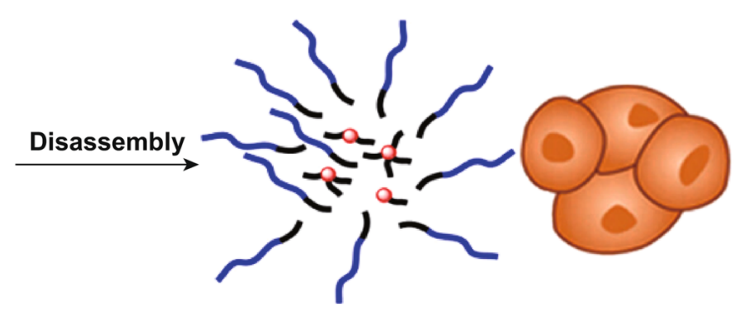

Cell apoptosis
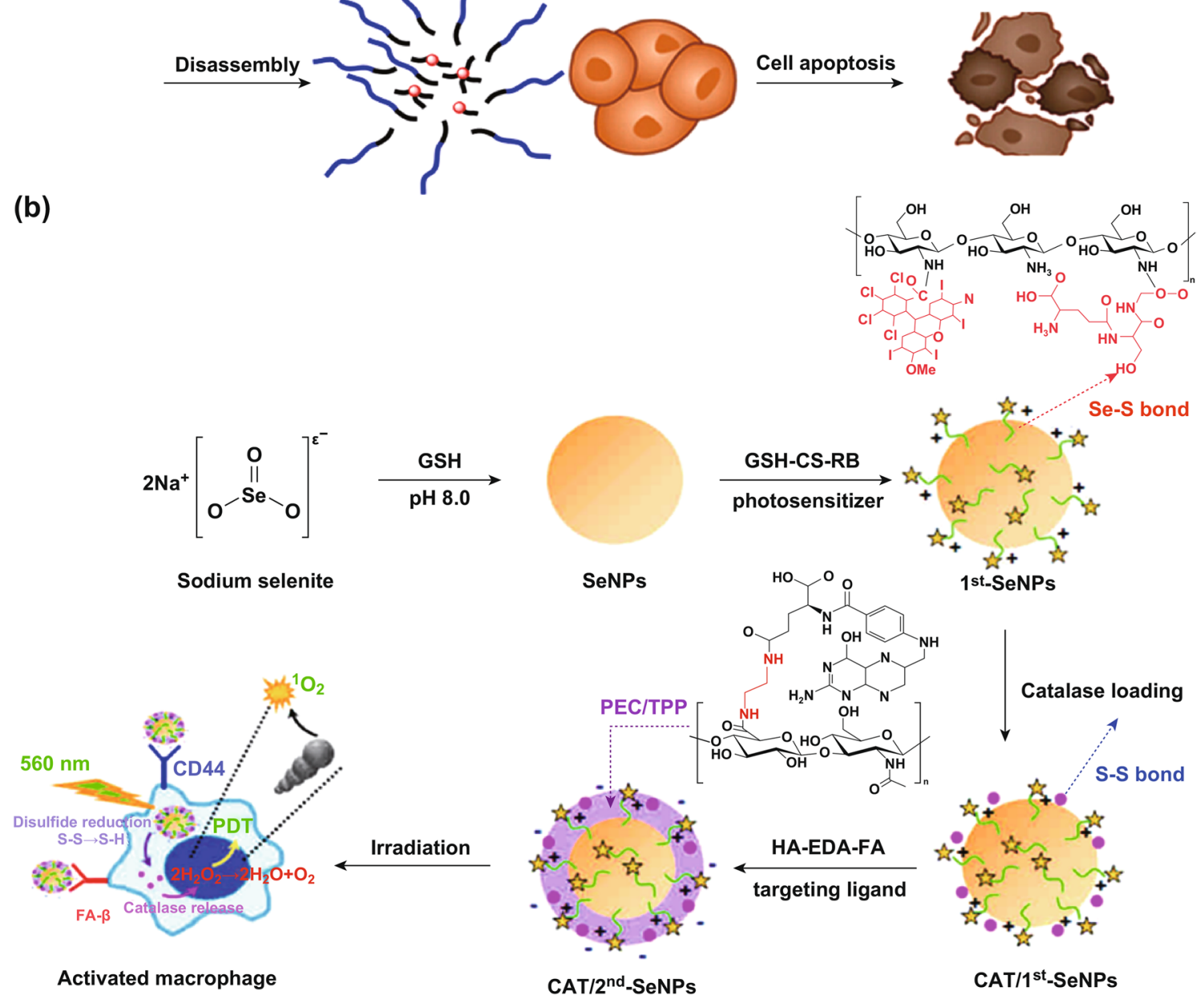

Fig. 13 a Schematic illustration of the formation of the PSe-Por micelles. After light irradiation, the oxidization product has anticancer activity. Adapted with permission from Ref. [69]. Copyright 2017 American Chemical Society. b Schematic diagrams for the preparation of catalaseloaded SeNPs and photodynamic treatment. Adapted with permission from Ref. [70]. Copyright 2017 American Chemical Society

polymer $(\mathrm{ABP})$ is the most promising drug delivery material due to its high physical loading capacity, adjustable size, and stable colloidal properties to prevent drug from inactivation. However, the drug release of ABP-based selfassembled micelles is slow and incomplete, which limits its application in cancer treatment. For enhanced therapeutic efficacy and reduced drug resistance, it is necessary to quickly release the cargo as completely as possible upon reaching the pathological site. To achieve this goal, a stimuli-responsive cleavage group, diselenide bond, is introduced into the MPEG-IPDI-Se-Se-IPDI-PPG. Due to the low bond energy of Se-Se, MPEG-IPDI-Se-Se-IPDI-PPG 
(a)

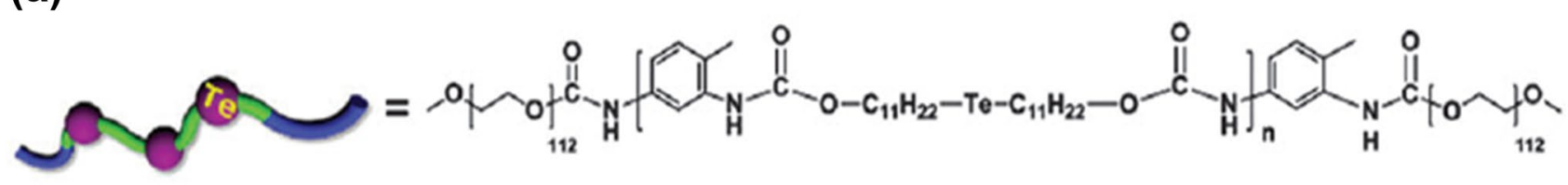

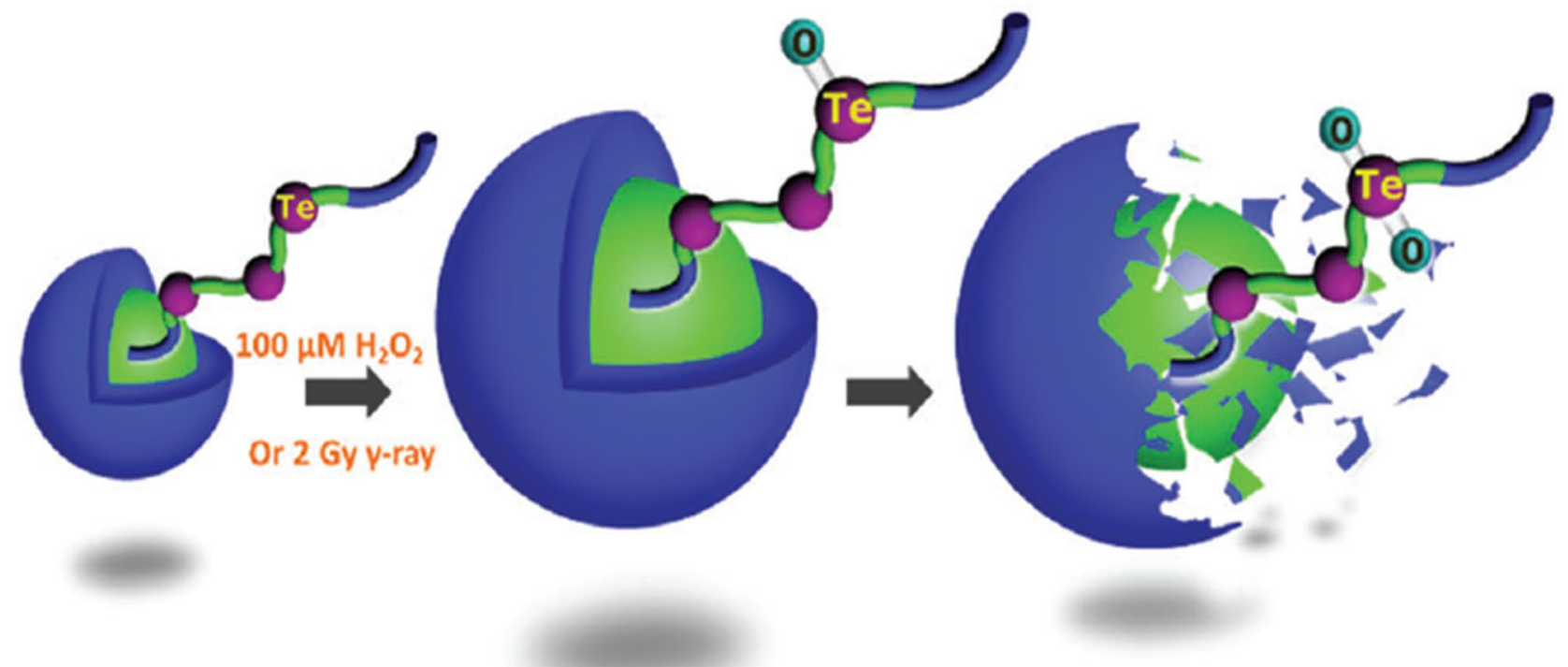

(b)

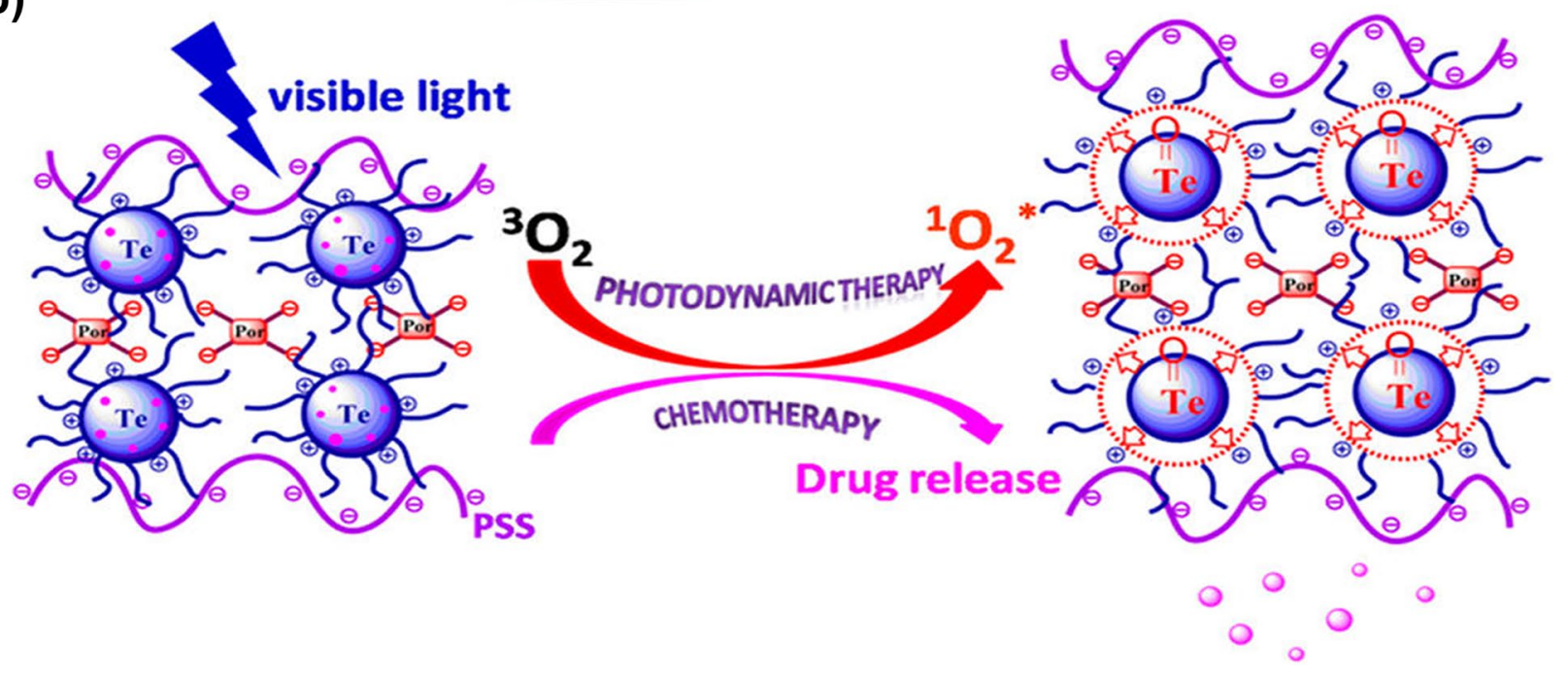

Fig. 14 a Oxidation-responsive organotellurium-containing polymer micelles that could undergo a series of morphological changes triggered by ROS under biologically relevant conditions. Adapted with permission from Ref. [72]. Copyright 2014 American Chemical Society. b Visible light-responsive tellurium-containing multilayer film. Adapted with permission from Ref. [73]. Copyright 2016 American Chemical Society

can be cleaved and oxidized to seleninic acid in the presence of oxidants and reduced to selenol in the presence of reductants. The change of the material in the system before and after the reaction of MPEG-IPDI-Se-Se-IPDI-PPG with 0.5 wt $\mathrm{H}_{2} \mathrm{O}_{2}$ was characterized by XPS analysis and ${ }^{1} \mathrm{H}-\mathrm{NMR}$ spectrum with $\mathrm{HOCH}_{2} \mathrm{CH}_{2} \mathrm{SeSeCH}_{2} \mathrm{CH}_{2} \mathrm{OH}$ as a reference. Confirm that $\mathrm{H}_{2} \mathrm{O}_{2}$ oxidizes the selenium bond to become selenite (Fig. 12b, c).

Moreover, Xu and co-workers successfully synthesized a series of $\mathrm{H}_{2} \mathrm{O}_{2}$-responsive block copolymers with seleniumbased groups located at the polymer main chains or side chains which can be used for enhancing tumor PDT. One of 
the prominent researches is a supra-amphiphile diselenidecontaining $\mathrm{H}_{2} \mathrm{O}_{2}$-responsive micelle (PSe-Por) with lightinduced cytotoxicity [69]. Loaded with porphyrin derivatives, PSe-Por was sensitive to ${ }^{1} \mathrm{O}_{2}$ when irradiated with visible light and could highly improve the use of singlet oxygen (Fig. 13a). Importantly, Mi's group has constructed an $\mathrm{H}_{2} \mathrm{O}_{2}$-depleting and $\mathrm{O}_{2}$-generating platform based on selenium nanoparticles for fluorescence imaging and PDT [70]. In this study, photodynamic selenium nanoparticles (SeNPs) with photosensitive and macrophage-targeting bilayers were developed. Conjugated with a PS rose bengaL (RB) and a thiolated chitosan (chitosan-glutathione) via disulfide bonds in the first layer, the absorption intensity of photosensitive macromolecule increases and its absorption band has a great redshift induced by plasmonic coupling. Reduction in disulfide bonds through the intercellular decomposition of $\mathrm{H}_{2} \mathrm{O}_{2}$ can generate a large amount of $\mathrm{O}_{2}$ and then produce ${ }^{1} \mathrm{O}_{2}$ under photoirradiation. Thus, the $\mathrm{H}_{2} \mathrm{O}_{2}$-depleting and $\mathrm{O}_{2}$-generating photodynamic SeNPs could efficiently kill activated macrophages, quenched the intracellular $\mathrm{H}_{2} \mathrm{O}_{2}$ and NO that are associated with inflammation and the SeNPs-based macromolecule may have potential as a theranostic nanomaterial in imaging and clinical applications (Fig. 13b). These open a new avenue for the development of $\mathrm{H}_{2} \mathrm{O}_{2}$-responsive drug delivery systems.

\subsubsection{Tellurium-Based Materials}

Tellurium-based materials with high selectivity and sensitivity toward $\mathrm{H}_{2} \mathrm{O}_{2}$ have been widely reported. As far as we know, most of them are inorganic materials. Similar to other organo-chalcogens, organotellurium-based compounds have been described as promising pharmacological agents due to their unique biological properties, especially for anticancer and antioxidant properties. Although plenty of evidence proves that they are presumed to have great potential for application in biological fields, there are few reports on the construction of the $\mathrm{H}_{2} \mathrm{O}_{2}$-responsive systems based on organotellurium to obtain desirable PDT efficacy.

$\mathrm{Xu}$ 's group has made a great contribution in this respect. Their first report about organotellurium-based stimuliresponsive polymer PEG-PUTe-PEG for controlled drug delivery systems was published in 2014 [71]. Competitive coordination of biomolecules can trigger the release of the loaded drug. This organotellurium-containing polymer, PEG-PUTe-PEG, swell and fracture dramatically when exposed to polyamines such as spermidine, arginine, and S-donor ligands such as biomolecules containing methionine and cysteine residues. This was confirmed by the variation of hydrodynamic diameters of the micelles. In order to confirm that the morphological transformation is caused by the oxidation of the telluride groups, ${ }^{1} \mathrm{H}$ NMR spectra was used to show the different chemical shifts of the telluriumcontaining segment. Based on these researches, in 2015 they successfully synthesized a series of $\mathrm{H}_{2} \mathrm{O}_{2}$-responsive block copolymers with selenium-based groups located at the polymer main chains or side chains which can be used as stimuli-responsive agents in drug delivery systems (Fig. 14a) [57, 72]. Moreover, they have also done some other studies based on organotellurium compounds for enhanced PDT [73]. Tellurium-containing photoresponsive polyelectrolyte multilayer films were fabricated by layerby-layer assembly of a tellurium-containing polymer, PS, and poly(styrenesulfonate). Under visible light, the PS in the film is excited and transforms triplet oxygen into singlet oxygen in aqueous solution, which is important to enhance the efficacy of PDT. Singlet oxygen oxidizes (-Te-) to high valence state $(\mathrm{Te}-\mathrm{O})$ on the polymer backbone. The generated $(\mathrm{Te}=\mathrm{O})$ group makes the micelles more hydrophilic and looser, thereby facilitating the controlled release of the loaded cargo of micelles. These results indicate that the film has the potential for cargo loading and controlled release, providing a new approach to the combined PDT/chemotherapy (Fig. 14b). Above all, these organotellurium-based compounds provide an excellent platform for future biological applications.

\section{Summary and Outlook}

In summary, $\mathrm{H}_{2} \mathrm{O}_{2}$ is an important endogenous ROS in human body and overproduced $\mathrm{H}_{2} \mathrm{O}_{2}$ is considered as a hallmark of malignancies. Importantly, $\mathrm{H}_{2} \mathrm{O}_{2}$ has also been studied as a stimulus in stimuli-responsive drug delivery systems. In this review, we have discussed the relationship between $\mathrm{H}_{2} \mathrm{O}_{2}$ and cancer briefly, and introduced the research progress of $\mathrm{H}_{2} \mathrm{O}_{2}$-responsive drug delivery system. More importantly, we summarized the emerging $\mathrm{H}_{2} \mathrm{O}_{2}$-responsive inorganic and organic materials for enhanced PDT. For inorganic materials, we have discussed 
the unique redox interaction between $\mathrm{H}_{2} \mathrm{O}_{2}$ and inorganic materials in detail, including multivalent metals Mn-, Au-, Pt-, Fe-, and Cu-based materials. Meanwhile, we emphasized their applications in enhanced PDT through distinct $\mathrm{H}_{2} \mathrm{O}_{2}$-responsive pathway. For organic-based materials, we discussed special functional bonds constructed from boron elements and sixth main group elements. The aryl boronic acids and their esters can be cleaved by $\mathrm{H}_{2} \mathrm{O}_{2}$ specifically, due to the strong oxidation performance of $\mathrm{H}_{2} \mathrm{O}_{2}$ and the electronegative property of sixth main group elements. With these achievements mentioned above, we firmly believe that these $\mathrm{H}_{2} \mathrm{O}_{2}$-responsive materials have great potential in enhancing anticancer PDT and they will play an important role in future cancer treatments. Further refinement of $\mathrm{H}_{2} \mathrm{O}_{2}$-responsive materials is also needed to make them more applicable to biomedical areas. At the same time, problems including tissue penetration depth, PS toxicity, tumor hypoxia, and short half-life of ${ }^{1} \mathrm{O}_{2}$ remain to be further studied and resolved.

Acknowledgements The work was supported by NNSF of China (61525402, 61775095, 51803091, 61935004), Jiangsu Provincial key research and development plan (BE2017741), Six talent peak innovation team in Jiangsu Province (TD-SWYY-009).

Open Access This article is licensed under a Creative Commons Attribution 4.0 International License, which permits use, sharing, adaptation, distribution and reproduction in any medium or format, as long as you give appropriate credit to the original author(s) and the source, provide a link to the Creative Commons licence, and indicate if changes were made. The images or other third party material in this article are included in the article's Creative Commons licence, unless indicated otherwise in a credit line to the material. If material is not included in the article's Creative Commons licence and your intended use is not permitted by statutory regulation or exceeds the permitted use, you will need to obtain permission directly from the copyright holder. To view a copy of this licence, visit http://creativecommons.org/licenses/by/4.0/.

\section{References}

1. K.D. Miller, R.L. Siegel, C.C. Lin, A.B. Mariotto, J.L. Kramer et al., Cancer treatment and survivorship statistics. CA Cancer J. Clin. 66(4), 271-289 (2016). https://doi.org/10.3322/ caac. 21349

2. D. Luo, K.A. Carter, D. Miranda, J.F. Lovell, Chemophototherapy: an emerging treatment option for solid tumors. Adv. Sci. 4(1), 1600106 (2017). https://doi.org/10.1002/advs.201600106

3. I.F. Tannock, C.M. Lee, J.K. Tunggal, D.S.M. Cowan, M.J. Egorin, Limited penetration of anticancer drugs through tumor tissue: a potential cause of resistance of solid tumors to chemotherapy. Clin. Cancer Res. 8(3), 878-884 (2002)

4. A.P. Castano, P. Mroz, M.R. Hamblin, Photodynamic therapy and anti-tumour immunity. Nat. Rev. Cancer 6(7), 535-545 (2006). https://doi.org/10.1038/nrc1894

5. P.N. Manghnani, W. Wu, S. Xu, F. Hu, C. The, B. Liu, Visualizing photodynamic therapy in transgenic zebrafish using organic nanoparticles with aggregation-induced emission. Nano-Micro Lett. 10, 61 (2018). https://doi.org/10.1007/s4082 0-018-0214-4

6. F. Chen, X. Zhuang, L. Lin, P. Yu, Y. Wang, Y. Shi, G. Hu, Y. Sun, New horizons in tumor microenvironment biology: challenges and opportunities. BMC Med. 13, 45 (2015). https ://doi.org/10.1186/s12916-015-0278-7

7. R. Mroue, M.J. Bissell, Three-dimensional cultures of mouse mammary epithelial cells. Methods Mol. Biol. 945, 221-250 (2013). https://doi.org/10.1007/978-1-62703-125-7_14

8. M. Wang, J. Zhao, L. Zhang, F. Wei, Y. Lian et al., Role of tumor microenvironment in tumorigenesis. J. Cancer 8(5), 761-773 (2017). https://doi.org/10.7150/jca.17648

9. D. Hanahan, R.A. Weinberg, Hallmarks of cancer: the next generation. Cell 144(5), 646-674 (2011). https://doi. org/10.1016/j.cell.2011.02.013

10. C.E. Weber, P.C. Kuo, The tumor microenvironment. Surg. Oncol. 21(3), 172-177 (2012). https://doi.org/10.1016/j.suron c.2011.09.001

11. M.V. Blagosklonny, Antiangiogenic therapy and tumor progression. Cancer Cell 5(1), 13-17 (2004). https://doi. org/10.1016/S1535-6108(03)00336-2

12. S. Xu, X. Zhu, C. Zhang, W. Huang, Y. Zhou, D. Yan, Oxygen and $\mathrm{Pt}(\mathrm{II})$ self-generating conjugate for synergistic photochemo therapy of hypoxic tumor. Nat. Commun. 9(1), 2053 (2018). https://doi.org/10.1038/s41467-018-04318-1

13. R. Weinstain, E.N. Sayariar, C.N. Felsen, R.Y. Tsien, In vivo targeting of hydrogen peroxide by activatable cell-penetrating peptides. J. Am. Chem. Soc. 136(3), 874-877 (2014). https://doi.org/10.1021/ja411547j

14. Q. Chen, L. Feng, J. Liu, W. Zhu, Z. Dong, Y. Wu, Z. Liu, Intelligent albumin- $\mathrm{MnO}_{2}$ nanoparticles as $\mathrm{pH}-/$ $\mathrm{H}_{2} \mathrm{O}_{2}$-responsive dissociable nanocarriers to modulate tumor hypoxia for effective combination therapy. Adv. Mater. 28(33), 7129-7136 (2016). https://doi.org/10.1002/ adma.201601902

15. J. Liu, Q. Chen, W. Zhu, X. Yi, Y. Yang, Z. Dong, Z. Liu, Nanoscale-coordination-polymer-shelled manganese dioxide composite nanoparticles: a multistage redox $/ \mathrm{pH} / \mathrm{H}_{2} \mathrm{O}_{2}$-responsive cancer theranostic nanoplatform. Adv. Funct. Mater. 27(10), 1605926 (2017). https://doi.org/10.1002/adfm.20160 5926

16. G. Csire, L. Nagy, K. Varnagy, C. Kallay, Copper(II) interaction with the human prion 103-112 fragment coordination and oxidation. J. Inorg. Biochem. 170, 195-201 (2017). https://doi. org/10.1016/j.jinorgbio.2017.02.018

17. Q.Y. Tang, W.Y. Xiao, C.H. Huang, W.L. Si, J.J. Shao et al., $\mathrm{pH}$-triggered and enhanced simultaneous photodynamic and 
photothermal therapy guided by photoacoustic and photothermal imaging. Chem. Mater. 29(12), 5216-5224 (2017). https ://doi.org/10.1021/acs.chemmater.7b01075

18. F. Wang, C. Li, J. Cheng, Z. Yuan, Recent advances on inorganic nanoparticle-based cancer therapeutic agents. Int. J. Environ. Res. Public Health 13(12), 1182 (2016). https://doi. org/10.3390/ijerph13121182

19. S.S. Lucky, K.C. Soo, Y. Zhang, Nanoparticles in photodynamic therapy. Chem. Rev. 115(4), 1990-2042 (2015). https ://doi.org/10.1021/cr5004198

20. P. Prasad, C.R. Gordijo, A.Z. Abbasi, A. Maeda, A. Ip, A.M. Rauth, R.S. DaCosta, X.Y. Wu, Multifunctional albumin$\mathrm{MnO}_{2}$ nanoparticles modulate solid tumor microenvironment by attenuating hypoxia, acidosis, vascular endothelial growth factor and enhance radiation response. ACS Nano 8(4), 32023212 (2014). https://doi.org/10.1021/nn405773r

21. Q. Tang, Z. Cheng, N. Yang, Q. Li, P. Wang et al., Hydrangeastructured tumor microenvironment responsive degradable nanoplatform for hypoxic tumor multimodal imaging and therapy. Biomaterials 205, 1-10 (2019). https://doi.org/10.1016/j. biomaterials.2019.03.005

22. H. Min, J. Wang, Y. Qi, Y. Zhang, X. Han et al., Biomimetic metal-organic framework nanoparticles for cooperative combination of antiangiogenesis and photodynamic therapy for enhanced efficacy. Adv. Mater. 31(15), e1808200 (2019). https ://doi.org/10.1002/adma.201808200

23. Z. Yuan, F. Lu, M. Peng, C.W. Wang, Y.T. Tseng et al., Selective colorimetric detection of hydrogen sulfide based on primary amine-active ester cross-linking of gold nanoparticles. Anal. Chem. 87(14), 7267-7273 (2015). https://doi. org/10.1021/acs.analchem.5b01302

24. G. Frens, Controlled nucleation for the regulation of the particle size in monodisperse gold suspensions. Nat. Phys. Sci. 241(105), 20-22 (1973). https://doi.org/10.1038/physci2410 $20 \mathrm{a} 0$

25. J. Turkevich, P.C. Stevenson, J. Hillier, A study of the nucleation and growth processes in the synthesis of colloidal gold. Disc. Faraday Soc. 11, 55-75 (1951). https://doi.org/10.1039/ df9511100055

26. Y. Sun, B.T. Mayers, Y. Xia, Template-engaged replacement reaction: a one-step approach to the large-scale synthesis of metal nanostructures with hollow interiors. Nano Lett. 2(5), 481-485 (2002). https://doi.org/10.1021/n1025531v

27. Y. Sun, Y. Xia, Shape-controlled synthesis of gold and silver nanoparticles. Science 298(5601), 2176-2179 (2002). https:// doi.org/10.1126/science.1077229

28. B. Nikoobakht, M.A. El-Sayed, Preparation and growth mechanism of gold nanorods (NRs) using seed-mediated growth method. Chem. Mater. 15(10), 1957-1962 (2003). https://doi. org/10.1021/cm0207321

29. A.K. Khan, R. Rashid, G. Murtaza, A. Zahra, Gold nanoparticles: synthesis and applications in drug delivery. Trop. J. Pharm. Res. 13(7), 1169-1177 (2014). https://doi.org/10.4314/ tjpr.v13i7.23

30. D. Pissuwan, S.M. Valenzuela, C.M. Miller, M.B. Cortie, A golden bullet? Selective targeting of toxoplasma gondii tachyzoites using anti body-functionalized gold nanorods. Nano Lett. 7(12), 3808-3812 (2007). https://doi.org/10.1021/ nl072377+

31. R. Vankayala, A. Sagadevan, P. Vijayaraghavan, C.-L. Kuo, K.C. Hwang, Metal nanoparticles sensitize the formation of singlet oxygen. Angew. Chem. Int. Ed. 50(45), 10640-10644 (2011). https://doi.org/10.1002/anie.201105236

32. C.-P. Liu, T.-H. Wu, C.-Y. Liu, K.-C. Chen, Y.-X. Chen, G.-S. Chen, S.-Y. Lin, Self-supplying O-2 through the catalase-like activity of gold nanoclusters for photodynamic therapy against hypoxic cancer cells. Small 13(26), 1700278 (2017). https:// doi.org/10.1002/smll.201700278

33. Q. Chen, J. Chen, Z. Yang, L. Zhang, Z. Dong, Z. Liu, NIRII light activated photodynamic therapy with protein-capped gold nanoclusters. Nano Res. 11(10), 5657-5669 (2018). https ://doi.org/10.1007/s12274-017-1917-4

34. J. Wei, J. Li, D. Sun, Q. Li, J. Ma et al., A novel theranostic nanoplatform based on Pd@Pt-PEG-Ce6 for enhanced photodynamic therapy by modulating tumor hypoxia microenvironment. Adv. Funct. Mater. 28(17), 1706310 (2018). https://doi. org/10.1002/adfm.201706310

35. X.-S. Wang, J.-Y. Zeng, M.-K. Zhang, X. Zeng, X.-Z. Zhang, A versatile Pt-based core-shell nanoplatform as a nanofactory for enhanced tumor therapy. Adv. Funct. Mater. 28(36), 1801783 (2018). https://doi.org/10.1002/adfm.201801783

36. W.-P. Li, C.-H. Su, Y.-C. Chang, Y.-J. Lin, C.-S. Yeh, Ultrasoundinduced reactive oxygen species mediated therapy and imaging using a fenton reaction activable polymersome. ACS Nano 10(2), 2017-2027 (2016). https://doi.org/10.1021/acsnano.5b06175

37. Z. Ma, M. Zhang, X. Jia, J. Bai, Y. Ruan, C. Wang, X. Sun, $\mathrm{X}$. Jiang, Fe-III-doped two-dimensional $\mathrm{C}_{3} \mathrm{~N}_{4}$ nanofusiform: a new $\mathrm{O}_{2}$-evolving and mitochondria-targeting photodynamic agent for MRI and enhanced antitumor therapy. Small 12(39), 5477-5487 (2016). https://doi.org/10.1002/smll.201601681

38. Y. Ruan, X. Jia, C. Wang, W. Zhen, X. Jiang, Mn-FE layered double hydroxide nanosheets: a new photothermal nanocarrier for $\mathrm{O}_{2}$-evolving phototherapy. Chem. Commun. 54(83), 11729-11732 (2018). https://doi.org/10.1039/C8CC06033A

39. P. Ma, H. Xiao, C. Yu, J. Liu, Z. Cheng et al., Enhanced cisplatin chemotherapy by iron oxide nanocarrier-mediated generation of highly toxic reactive oxygen species. Nano Lett. 17(2), 928-937 (2017). https://doi.org/10.1021/acs.nanolett.6b04269

40. N. Masomboon, C. Ratanatamskul, M.C. Lu, Chemical oxidation of 2,6-dimethylaniline in the fenton process. Environ. Sci. Technol. 43(22), 8629-8634 (2009). https://doi.org/10.1021/ es802274h

41. E. Brillas, M.A. Baños, S. Camps, C. Arias, P.-L. Cabot, J.A. Garrido, R.M. Rodríguez, Catalytic effect of $\mathrm{Fe}^{2+}, \mathrm{Cu}^{2+}$ and UVA light on the electrochemical degradation of nitrobenzene using an oxygen-diffusion cathode. New J. Chem. 28(2), 314-322 (2004). https://doi.org/10.1039/B312445B

42. T. Soltani, B.-K. Lee, Enhanced formation of sulfate radicals by metal-doped $\mathrm{BiFeO}_{3}$ under visible light for improving photo-fenton catalytic degradation of 2-chlorophenol. Chem. Eng. J. 313, 1258-1268 (2017). https://doi.org/10.1016/j. cej.2016.11.016 
43. B. Ma, S. Wang, F. Liu, S. Zhang, J. Duan et al., Self-assembled copper-amino acid nanoparticles for in situ glutathione "and" $\mathrm{H}_{2} \mathrm{O}_{2}$ sequentially triggered chemodynamic therapy. J. Am. Chem. Soc. 141(2), 849-857 (2018). https://doi. org/10.1021/jacs.8b08714

44. C. Wang, F. Cao, Y. Ruan, X. Jia, W. Zhen, X. Jiang, Specific generation of singlet oxygen through the russell mechanism in hypoxic tumors and GSH depletion by $\mathrm{Cu}$-TCPP nanosheets for cancer therapy. Angew. Chem. Int. Ed. 131(29), 99519955 (2019). https://doi.org/10.1002/ange.201903981

45. Y. Fan, P. Li, B. Hu, T. Liu, Z. Huang et al., A smart photosensitizer-cerium oxide nanoprobe for highly selective and efficient photodynamic therapy. Inorg. Chem. 58(11), 7295-7302 (2019). https://doi.org/10.1021/acs.inorgchem.9b00363

46. Y. Li, L. An, J. Lin, Q. Tian, S. Yang, Smart nanomedicine agents for cancer, triggered by $\mathrm{pH}$, glutathione, $\mathrm{H}_{2} \mathrm{O}_{2}$, or $\mathrm{H}_{2}$ S. Int. J. Nanomed. 14, 5729-5749 (2019). https://doi. org/10.2147/IJN.S210116

47. Y. Zeng, W. Zeng, Q. Zhou, X. Jia, J. Li, Z. Yang, Y. Hao, J. Liu, Hyaluronic acid mediated biomineralization of multifunctional ceria nanocomposites as ROS scavengers and tumor photodynamic therapy agents. J. Mater. Chem. B 7(20), 3210-3219 (2019). https://doi.org/10.1039/C8TB03374A

48. T. Jia, J. Xu, S. Dong, F. He, C. Zhong et al., Mesoporous cerium oxide-coated upconversion nanoparticles for tumorresponsive chemo-photodynamic therapy and bioimaging. Chem. Sci. 10(37), 8618-8633 (2019). https://doi.org/10.1039/ C9SC01615E

49. W. Jiang, C. Zhang, A. Ahmed, Y. Zhao, Y. Deng, Y. Ding, J. Cai, Y. Hu, $\mathrm{H}_{2} \mathrm{O}_{2}$-sensitive upconversion nanocluster bomb for tri-mode imaging-guided photodynamic therapy in deep tumor tissue. Adv. Healthc. Mater. 8(20), e1900972 (2019). https://doi.org/10.1002/adhm.201900972

50. X. Lu, M. Zhao, P. Chen, Q. Fan, W. Wang, W. Huang, Enhancing hydrophilicity of photoacoustic probes for effective ratiometric imaging of hydrogen peroxide. J. Mater. Chem. B 6(27), 4531-4538 (2018). https://doi.org/10.1039/C8TB0 $1158 \mathrm{C}$

51. X. Shang, X. Song, C. Faller, R. Lai, H. Li, R. Cerny, W. Niu, J. Guo, Fluorogenic protein labeling using a genetically encoded unstrained alkene. Chem. Sci. 8(2), 1141-1145 (2017). https://doi.org/10.1039/C6SC03635J

52. H. Ren, Y. Wu, Y. Li, W. Cao, Z. Sun, H. Xu, X. Zhang, Visible-light-induced disruption of diselenide-containing layer-bylayer films: toward combination of chemotherapy and photodynamic therapy. Small 9(23), 3981-3986 (2013). https://doi. org/10.1002/smll.201300628

53. R.L. Cunha, I.E. Gouvea, L. Juliano, A glimpse on biological activities of tellurium compounds. An. Acad. Bras. Cienc. 81(3), 393-407 (2009). https://doi.org/10.1590/ S0001-37652009000300006

54. C. Li, R. Pan, P. Li, Q. Guan, J. Ao et al., Hydrogen peroxide-responsive nanoprobe assists circulating tumor cell identification and colorectal cancer diagnosis. Anal. Chem. 89(11), 5966-5975 (2017). https://doi.org/10.1021/acs.analc hem. $7 \mathrm{~b} 00497$
55. Y. Kuang, K. Baakrishnan, V. Gandhi, X. Peng, Hydrogen peroxide inducible DNA cross-linking agents: targeted anticancer prodrugs. J. Am. Chem. Soc. 133(48), 19278-19281 (2011). https://doi.org/10.1021/ja2073824

56. J. Noh, B. Kwon, E. Han, M. Park, W. Yang et al., Amplification of oxidative stress by a dual stimuli-responsive hybrid drug enhances cancer cell death. Nat. Commun. 6, 6907 (2015). https://doi.org/10.1038/ncomms7907

57. G. Saravanakumar, J. Kim, W.J. Kim, Reactive-oxygenspecies-responsive drug delivery systems: promises and challenges. Adv. Sci. 4(1), 1600124 (2017). https://doi. org/10.1002/advs.201600124

58. D. Gonzalez-Ballester, A.R. Grossman, in Chapter 5-sulfur: From Acquisition to Assimilation, ed. by E.H. Harris, D.B. Stern, G.B. Witman (Academic Press, London, 2009), pp. 159-187 https://doi.org/10.1016/B978-0-12-37087 3-1.00013-7

59. U. Tinggi, Selenium: its role as antioxidant in human health. Environ. Health Prev. Med. 13(2), 102-108 (2008). https:// doi.org/10.1007/s12199-007-0019-4

60. L. Wang, W. Wang, W. Cao, H. Xu, Multi-hierarchical responsive polymers: stepwise oxidation of a selenium- and tellurium-containing block copolymer with sensitivity to both chemical and electrochemical stimuli. Polym. Chem. 8(31), 4520-4527 (2017). https://doi.org/10.1039/C7PY00971B

61. L. Wang, X. Qu, Y. Xie, S. Lv, Study of 8 types of glutathione peroxidase mimics based on $\beta$-cyclodextrin. Catalysts 7(10), 289 (2017). https://doi.org/10.3390/catal7100289

62. D. Lee, S. Bae, Q. Ke, J. Lee, B. Song et al., Hydrogen peroxide-responsive copolyoxalate nanoparticles for detection and therapy of ischemia-reperfusion injury. J. Control. Release 172(3), 1102-1110 (2013). https://doi.org/10.1016/j.jconr el.2013.09.020

63. D. Mao, W. Wu, S. Ji, C. Chen, F. Hu, D. Kong, D. Ding, B. Liu, Chemiluminescence-guided cancer therapy using a chemiexcited photosensitizer. Chem 3(6), 991-1007 (2017). https ://doi.org/10.1016/j.chempr.2017.10.002

64. B. Liu, D. Wang, Y. Liu, Q. Zhang, L. Meng et al., Hydrogen peroxide-responsive anticancer hyperbranched polymer micelles for enhanced cell apoptosis. Polym. Chem. 6(18), 3460-3471 (2015). https://doi.org/10.1039/C5PY00257E

65. J. Wang, H. He, X. Xu, X. Wang, Y. Chen, L. Yin, Far-red light-mediated programmable anti-cancer gene delivery in cooperation with photodynamic therapy. Biomaterials 171, 72-82 (2018). https://doi.org/10.1016/j.biomateria 1s.2018.04.020

66. M. Iwaoka, S. Tomoda, A model study on the effect of an amino group on the antioxidant activity of glutathione-peroxidase. J. Am. Chem. Soc. 116(6), 2557-2561 (1994). https:// doi.org/10.1021/ja00085a040

67. T. Sun, Y. Jin, R. Qi, S. Peng, B. Fan, Oxidation responsive mono-cleavable amphiphilic di-block polymer micelles labeled with a single diselenide. Polym. Chem. 4(14), 40174023 (2013). https://doi.org/10.1039/c3py00406f

68. T. Sun, Y. Jin, R. Qi, S. Peng, B. Fan, Post-assembly of oxidation-responsive amphiphilic triblock polymer containing 
a single diselenide. Macromol. Chem. Phys. 214(24), 28752881 (2013). https://doi.org/10.1002/macp.201300579

69. C. Sun, S. Ji, F. Li, H. Xu, Diselenide-containing hyperbranched polymer with light-induced cytotoxicity. ACS Appl. Mater. Interfaces. 9(15), 12924-12929 (2017). https://doi. org/10.1021/acsami.7b02367

70. K.Y. Lu, P.Y. Lin, E.Y. Chuang, C.M. Shih, T.M. Cheng et al., $\mathrm{H}_{2} \mathrm{O}_{2}$-depleting and $\mathrm{O}_{2}$-generating selenium nanoparticles for fluorescence imaging and photodynamic treatment of proinflammatory-activated macrophages. ACS Appl. Mater. Interfaces. 9(6), 5158-5172 (2017). https://doi.org/10.1021/acsam i. $6 \mathrm{~b} 15515$
71. W. Cao, Y. Gu, M. Meineck, T. Li, H. Xu, Tellurium-containing polymer micelles: competitive-ligand-regulated coordination responsive systems. J. Am. Chem. Soc. 136(13), 5132-5137 (2014). https://doi.org/10.1021/ja500939m

72. W. Cao, Y. Gu, T. Li, H. Xu, Ultra-sensitive ros-responsive tellurium-containing polymers. Chem. Commun. 51(32), 7069-7071 (2015). https://doi.org/10.1039/C5CC01779C

73. F. Fan, L. Wang, F. Li, Y. Fu, H. Xu, Stimuli-responsive layerby-layer tellurium-containing polymer films for the combination of chemotherapy and photodynamic therapy. ACS Appl. Mater. Interfaces. 8(26), 17004-17010 (2016). https://doi. org/10.1021/acsami.6b04998 